\title{
An integrated assessment of seismic hazard exposure and its societal impact in Seven Sister States of North Eastern Region of India for sustainable disaster mitigation planning
}

Navdeep Agrawal

Shiv Nadar University

Laxmi Gupta

Shiv Nadar University

Jagabandhu Dixit ( $\square$ jagabandhu.dixit@snu.edu.in )

Shiv Nadar University https://orcid.org/0000-0002-5450-578X

Sujit Kumar Dash

Indian Institute of Technology Kharagpur

\section{Research Article}

Keywords: North East India, seismic hazard, social vulnerability index, cluster analysis, seismic exposure

Posted Date: October 21st, 2021

DOI: https://doi.org/10.21203/rs.3.rs-1003515/v1

License: (c) (1) This work is licensed under a Creative Commons Attribution 4.0 International License.

Read Full License 
1 An integrated assessment of seismic hazard exposure and its societal impact in Seven

2 Sister States of North Eastern Region of India for sustainable disaster mitigation 3 planning

$4 \quad$ Navdeep Agrawal ${ }^{1}$, Laxmi Gupta ${ }^{1}$, Jagabandhu Dixit ${ }^{1, *}$, Sujit Kumar Dash ${ }^{2}$

$5 \quad{ }^{1}$ Disaster Management Laboratory, Shiv Nadar University, Delhi NCR, Greater Noida, Uttar $6 \quad$ Pradesh 201314, India.

$7 \quad{ }^{2}$ Department of Civil Engineering, Indian Institute of Technology Kharagpur, Kharagpur, $8 \quad$ West Bengal 721302, India.

9 E-mail address of authors: na655@snu.edu.in; 1g100@snu.edu.in; sujit@civil.iitkgp.ac.in

*Corresponding Author: Jagabandhu Dixit, Email: jagabandhu.dixit@snu.edu.in

\section{Abstract}

The Seven Sister States of the North Eastern Region of India, located on the complex seismotectonic belt, is characterized by high seismicity. A comprehensive seismic hazard exposure assessment is carried out by quantifying hazard using a probabilistic approach, vulnerability by factor analysis, and exposure mapping by integrating seismic hazard and vulnerability. Peak ground acceleration (PGA) values at bedrock are calculated with the help of ground motion prediction equations (GMPE) for $10 \%$ probability of exceedance in 50 years (475 years) and 100 years (950 years), and 2\% probability of exceedance in 50 years (2475 years). The resulting spatial distribution of the PGA values considering return periods of 475, 950, and 2475 years are presented through seismic hazard maps. The social vulnerability analysis indicates that 21 districts covering 91.43\% area of the state of Assam and the entire state of Tripura are under high vulnerability. With the help of spatial cluster analysis, it is found 
24 that $17.14 \%$ of the study area are having an average social vulnerability index (SVI) score of

250.329 and therefore can be considered as hotspots. Through seismic hazard analysis, it is observed that more than $50 \%$ of the area of North East India is under moderate to very high

27 exposure class. The seismic hazard maps developed can help in disaster mitigation planning 28 and execution leading to sustainable development goals and targets.

29 Keywords: North East India, seismic hazard, social vulnerability index, cluster analysis, seismic exposure

\section{Introduction}

32 The North Eastern Region (NER) of India comprises eight states, namely Arunachal Pradesh, 33 Assam, Manipur, Meghalaya, Mizoram, Nagaland, Tripura, and Sikkim. The Seven Sister 34 States (SSS) of India is a popular term for the seven contiguous states in NER except for 35 Sikkim. The Himalayan arc ranges, extending from west-northwest to east-southeast of India, 36 lies near the subduction zone of Indian and Eurasian tectonic plates. Due to the collision of the

37 Indian plate with the Tibet plateau towards the northern part and the Burmese landmass towards the east, the formation of seismotectonic features like the Himalayan thrust, Arakan-Yoma, Naga Hills, and Tripura fold have resulted (Verma and Kumar 1987). The Himalayan tectonic 40 feature in north-eastern India is very complex and exhibits high seismicity. Due to its 41 geological, geomorphological, and seismotectonic setting, the NER is highly exposed to 42 seismic hazards. The region has suffered extensive loss of lives and damage to property due to significant earthquakes in the past. On 28 April 2021, an $M_{w} 6.0$ earthquake occurred near Dhekiajuli in Assam, India, leading to ground cracking and the collapse of several houses. For

45 the past few decades, The NER has been experiencing high seismic risk, which can be 46 attributed to an increase in population density and unplanned rapid urbanization and 47 infrastructure developments. 
48 Quantifying seismic risk by assessment of hazard and vulnerability at a regional level is a significant step towards effective disaster risk reduction and mitigation strategies. Seismic hazard deals with the quantification of ground motion at a particular site in a specific time 51 interval which can be expressed in terms of peak ground acceleration (PGA) or spectral 52 acceleration (SA), or any other ground motion parameter (GMP) (Kramer 1996). The vulnerability could be either social or physical. However, it is primarily defined by the social, economic, natural, and built environmental conditions of a community that affects its susceptibility towards the hazards significantly (Cutter et al. 2008). The physical vulnerability deals with the building stock in the vicinity and their susceptibility to hazard. In contrast, social vulnerability is concerned with identifying vulnerable groups of the society in the region and the factors that can affect it directly or indirectly (Cutter 1996). Therefore, the combined study of seismic hazard and social vulnerability will enable the policymakers, urban planners, and other concerned authorities to pre-identify the localities prone to high potential seismic hazards. Moreover, such a study shall help in understanding the impact of the seismic hazard on the lives of the people living in the vicinity of such disaster-prone areas. In the past, many researchers like Sharma and Malik (2006), Raghukanth and Dash (2010), NDMA (2010), Raghukanth et al. (2011), Nath and Thingbaijam (2012), Das et al. (2016), Dixit et al. (2016), and Ghione et al. (2021) have contributed to different aspects of seismic risk assessment for the NER of India with a common goal to reduce the disaster risk. At the regional level, such seismic hazard studies are also available, Sitharam and Sil (2014) for the state of Tripura and Mizoram; Baro et al. (2018) for the Shillong Plateau, Meghalaya; Bahuguna; and Sil (2020) for the state of Assam. However, these studies have only focused on the seismic hazard assessment, either deterministically (DSHA) or probabilistically (PSHA),

71 but have not considered the vulnerability aspect which is an equally important issue.

72 Worldwide, several studies have been conducted on social vulnerability in regards to seismic 
hazard by considering different assessment frameworks like the Hazard of Place Model, HoP (Cutter 1996), the BBC model (Brikmann 2013), Disaster of Resilience of Place model, DROP (Cutter et al. 2008), and methods like multicriteria analysis, MCA (Martins et al. 2012; Frigerio et al. 2016; Armas and Gavris 2017; Derakhshan et al. 2020; and Agrawal et al. 2021). In the Indian scenario, most seismic hazard vulnerability studies are directed towards the built environment (Sarmah and Das 2018; Dutta, Halder, and Sharma 2021). For NER, social vulnerability assessment (SVA) due to climate change and environmental hazards were performed by Maiti et al. (2017) and Das et al. (2021), respectively. However, social vulnerability studies of the NER due to seismic hazards are very limited. This is primarily because such studies involve diverse seismic and demographic databases which are relatively difficult to obtain. The present study has investigated this issue through probabilistic seismic hazard analysis and social vulnerability studies.

The objective of the present study is to develop the updated seismic hazard map of the Seven Sister States of northeast India using PSHA based on the updated earthquake catalogue and conduct social vulnerability assessment and exposure to seismic hazard. A circle of radius 500 $\mathrm{km}$ (around $26.16^{\circ} \mathrm{N}$ and $93.28^{\circ} \mathrm{E}$ ) covering the entire NER is constructed for the development of the seismotectonic model, and the region is segmented into $0.2^{\circ} \mathrm{x} 0.2^{\circ}$ grids (Anbazhagan et al. 2019). Following the PSHA approach, the seismic hazard is assessed at the center of each grid. The data obtained is then utilized to quantify the PGA values at the bedrock level for $10 \%$ probability of exceedance in 50 and 100 years and $2 \%$ probability of exceedance in 50 years. Subsequently, the PGA values are plotted in the GIS environment leading to seismic hazard maps.

For SVA, the indicators are selected by the application of principal component analysis (PCA) and factor analysis (FA) within the framework of the HoP model for the generation of the social vulnerability index, SVI (Agrawal et al. 2021). Additionally, with the help of spatial statistical 
and cluster analysis tools in the GIS environment, hotspot and cold spot clusters within the

99

100

101

102 study area are identified. Finally, the seismic hazard map is integrated with the SVI, and exposure maps for the NER are developed.

\section{Study Area}

The present study area consists of the Seven Sister States (SSS) of northeast India, namely, Arunachal Pradesh, Assam, Manipur, Meghalaya, Mizoram, Nagaland, and Tripura. It lies between $20^{\circ} \mathrm{N}-30^{\circ} \mathrm{N}$ latitude and $87^{\circ} \mathrm{E}-98^{\circ} \mathrm{E}$ longitude (Fig. 1). Geographically, it can be classified into the Eastern Himalayas, Barak valley, Patkai hills, and Brahmaputra valley plains (Verma 2018).

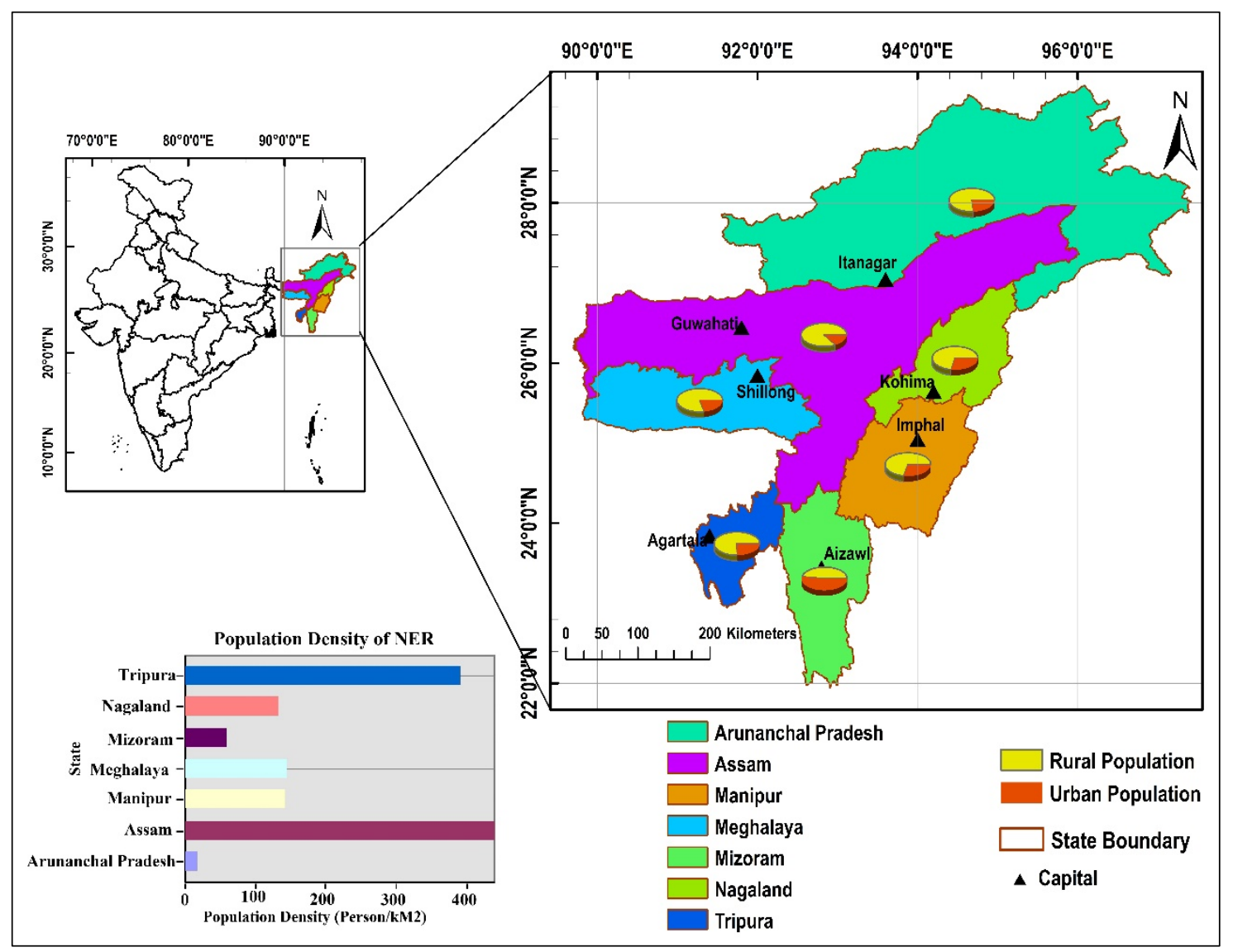

Fig. 1 Study area: Seven Sister States in NER of India

The presence of the Indo-Burmese plate boundary in the eastern region and the Indo-Eurasian plate boundary in the northern region (Baro et al. 2018), makes the NER one of the most seismically active regions in the world. As per IS1893 (2016), it is categorized as the most 
severe seismic zone in India i.e. zone V. Its tectonic setting is shown in Fig. 2. In the past,

113 several high-intensity earthquakes such as the 1869 Cachar earthquake, 1897 Shillong 114 earthquake, 1918 Meghalaya earthquake, 1947 Arunachal Pradesh earthquake, and 1950 115 Assam earthquake; have severely affected this region.

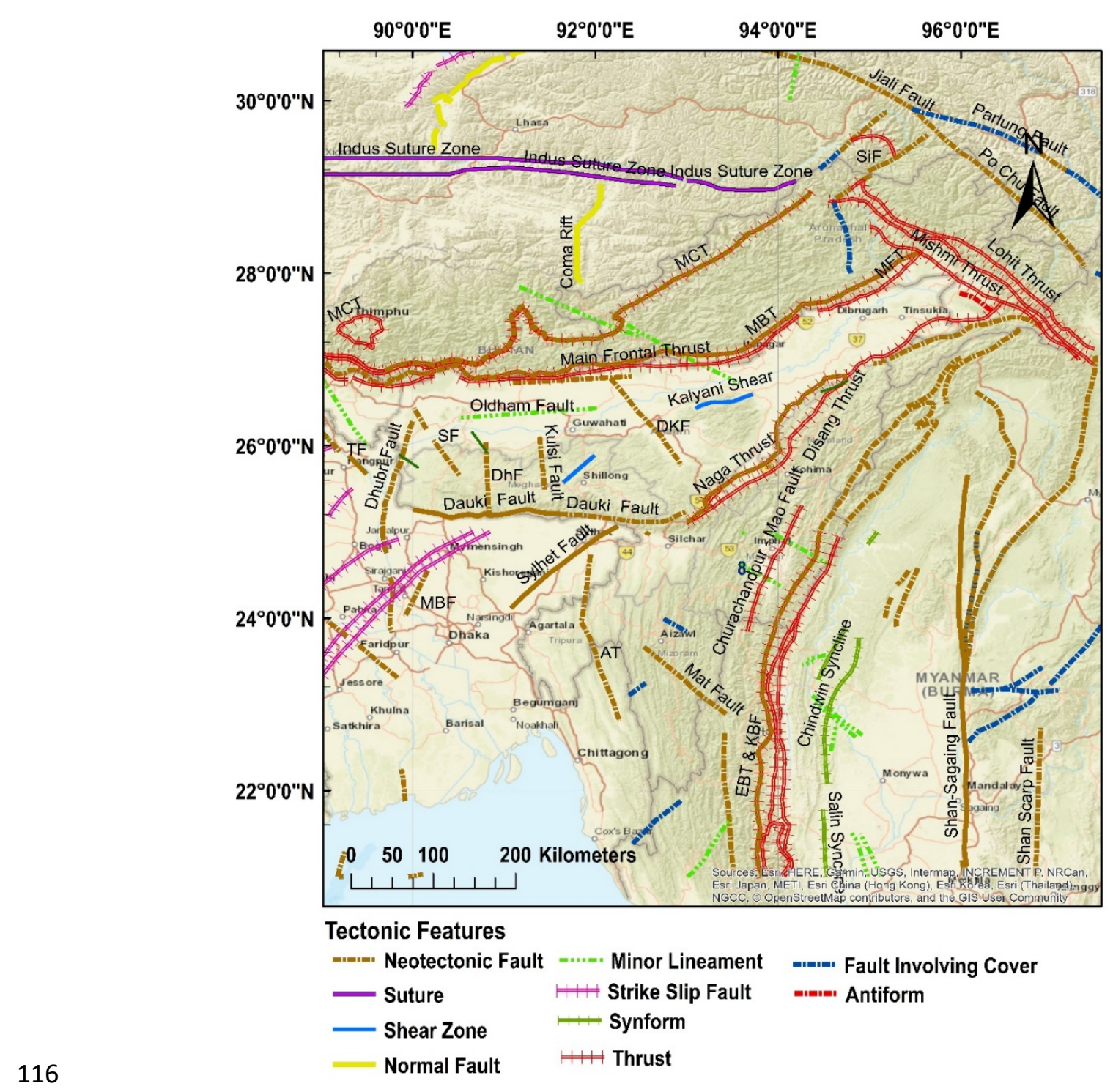

Fig. 2 Seismotectonic features of NER of India

118 In all states of the SSS, except Mizoram, more than 70\% population live in rural areas (Census 119 2011). The primary source of their economy is agriculture. This is because due to inaccessible terrain and lack of transportation networks, few industries have developed in this region. High population density is observed in the states of Assam and Tripura with 439.43 and 389.11 
people per sq. km, respectively, which is possibly due to the presence of better employment opportunities. In Arunachal Pradesh and Mizoram, the population density is the lowest i.e. 17.26, 58.90 people per sq. km, respectively (Fig.1). The population of Assam constitutes more than $65 \%$ of the total population of the SSS region (Census 2011). High population growth, increased infrastructure, unplanned urbanization, and complex seismotectonic regime tends to increase the seismic risk of this region. Therefore, a comprehensive seismic hazard analysis and social vulnerability assessment at the regional level is highly essential for effective disaster risk management leading to the reduction of loss of lives and property.

\section{Methodology}

The present study consists of (a) seismic hazard assessment, (b) social vulnerability assessment, and (c) quantification of exposure to the seismic hazard; details of which are presented below.

\subsection{Seismic Hazard Assessment (SHA)}

The probabilistic approach (PSHA), adopted in the present study, can effectively consider the uncertainties in the earthquake magnitude, location, and time of occurrence, etc. Like DSHA, PSHA does not focus on an exclusive event for worst-case scenarios; instead, it contemplates all possible earthquakes from all potential seismic sources. For PSHA, seismicity of each source zone, uncertainties in location, size, and ground motion to obtain the probability that a GMP will be exceeded during a particular period is taken into account (Kramer 1996).

\subsubsection{Data Acquisition}

The earthquake catalogue for the NER is compiled over an area of radius of $500 \mathrm{~km}$, centered around the coordinate point of $26.16^{\circ} \mathrm{N}$ and $93.28^{\circ} \mathrm{E}$. The details of 8959 earthquake events from 1760 to 2021 (261 years) were obtained from the databases like the National Center for Seismology (NCS), India, Bhukosh-Geological Survey of India, United States Geological 
146 Survey (USGS), and International Seismological Center (ISC), etc. The compiled catalogue 147 comprises events in different magnitude scales, like body-wave magnitude $\left(m_{b}\right)$, surface-wave 148 magnitude $\left(M_{S}\right)$, local magnitude $\left(M_{L}\right)$, and moment magnitude scale $\left(M_{w}\right)$. For a rational 149 seismic hazard analysis, a uniform magnitude scale is necessary the details of which are 150 explained below.

151

152 153 154 155

157

158

159

160

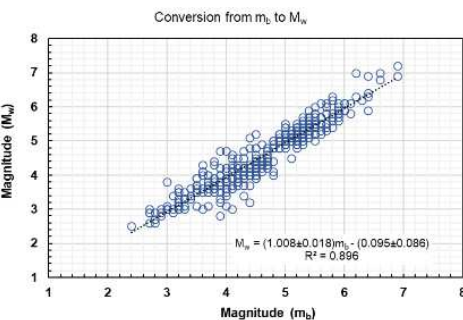

(a)

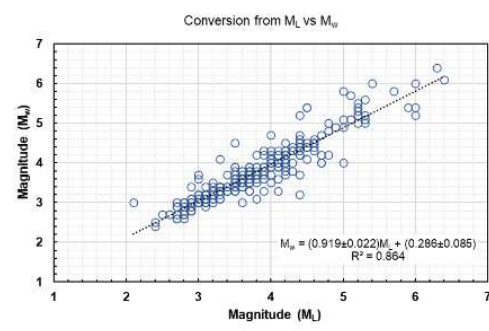

(b)

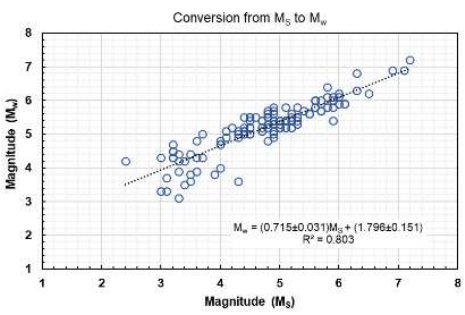

(c)

Fig. 3 Conversion from (a) $m_{b}$ to $M_{w}$, (b) $M_{L}$ to $M_{w}$, and (c) $M_{S}$ to $M_{w}$

Table 1 Relation between different magnitude scales

\begin{tabular}{ccccc}
\hline Scale & data points & Relation & $\mathrm{R}^{2}$ \\
\hline$m_{b}$ to $M_{w}$ & 349 & $M_{w}=(1.008 \pm 0.018) m_{b}-(0.095 \pm 0.086)$ & $2.4 \leq \mathrm{m}_{\mathrm{b}} \leq 6.9$ & 0.896 \\
& & $M_{w}=(0.919 \pm 0.022) M_{L}+$ & \\
$M_{L}$ to $M_{w}$ & 277 & $(0.286 \pm 0.085)$ & $2.5 \leq M_{L} \leq 7.0$ & 0.864 \\
& & $M_{w}=(0.715 \pm 0.031) M_{S}+$ & $3.0 \leq M_{S} \leq$ & \\
$M_{S}$ to $M_{w}$ & 130 & $(1.796 \pm 0.151)$ & 7.2 & 0.803 \\
& & & & \\
\hline
\end{tabular}


162 From the unified earthquake catalogue, the foreshocks and aftershocks are removed by

163 declustering as they are dependent on the mainshock, spatially and temporally (Zhuang, Ogata

164 and Vere-Jones 2002). In this study, an open-source software ZMAP (v7.0) by Wiemer (2001)

165 is utilized to eliminate the dependent events by following the methodology proposed by

166 Gardner and Knopoff (1974) which follows a Poisson distribution (Stiphout et al. 2012). A

167 similar procedure has been followed by Sitharam and Sil (2014), and Anbazhagan et al. 2019.

168 After declustering, it was found that $26.34 \%$ of the events are interdependent and, therefore,

169 were eliminated from the data set. Consequently, only 6599 events are retained in the dataset, among which 4837 events are greater than $M_{w} 3.5$.

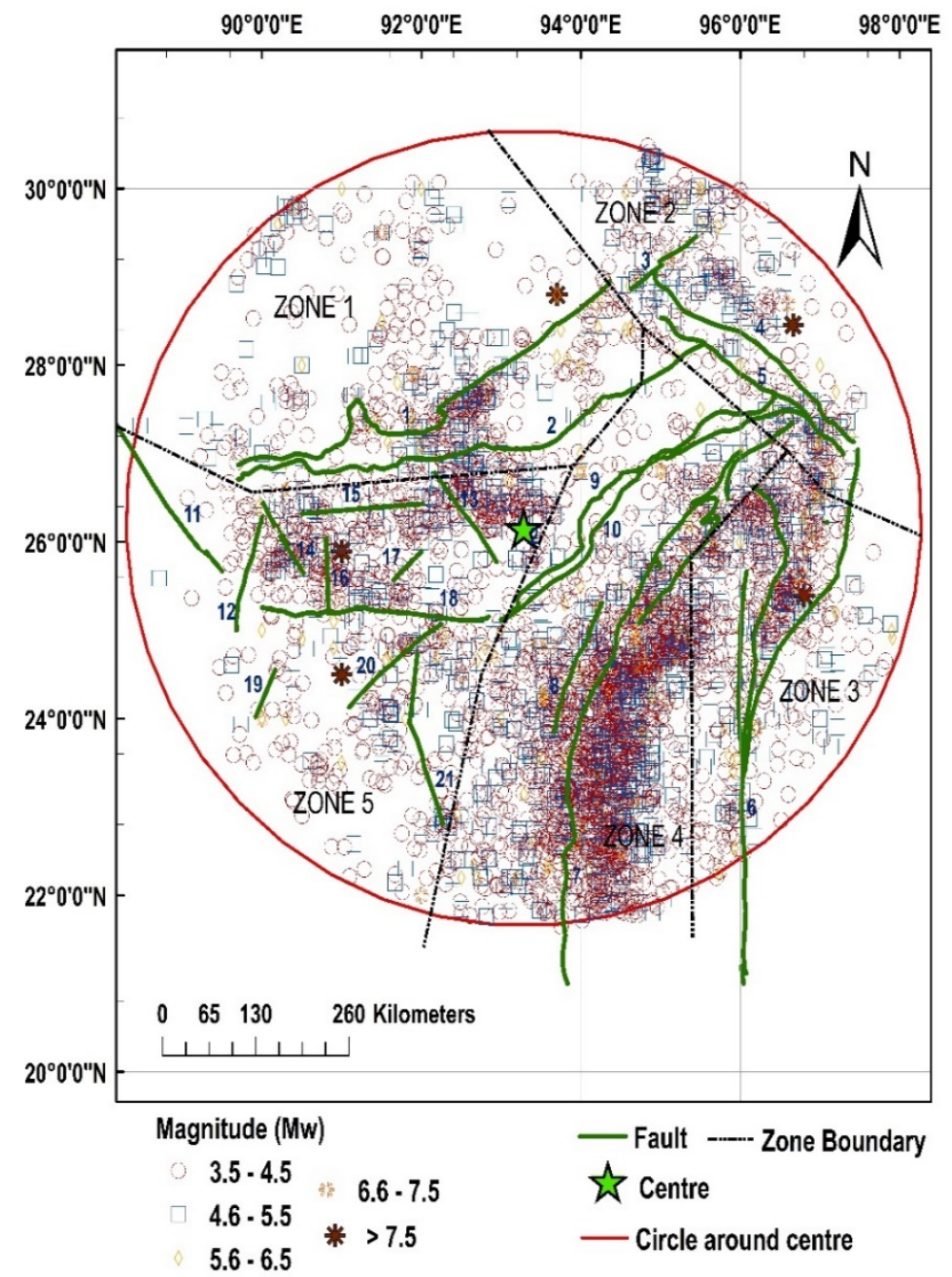

Fig. 4 Seismic source zone demarcation with major faults and declusteredhomogenized earthquake 


\subsubsection{Seismic Source Zonation}

175 Seismic source zonation is considered an essential pre-requirement for the seismic hazard 176 study. In the present study, the study area is divided into five source zones that are distinct in 177 terms of fault properties, seismic source, geology, and plate tectonics (Fig. 4).

\subsubsection{Completeness of Catalogue}

179 For PSHA, it is also necessary to check for completeness of the data in terms of magnitude and 180 time. The magnitude of completeness $(M c)$ is the lowest magnitude above which the catalogue, in a selected space-time window, is considered to be complete (Rydelek and Sacks 1989;

Wiemer and Wyss 2000). $M_{C}$, in the present study, is obtained through the maximum curvature method (MAXC). A similar procedure has been adopted by various scholars worldwide (Woessner and Wiemer 2005). The open-source software ZMAP (v 7.0) by Wiemer (2001) was used for this purpose and the obtained values of the $M_{C}$ are presented in Table 2.

The completeness study of seismic data in terms of time, as shown in Fig. 5, was performed using the statistical analysis proposed by Stepp (1972). The magnitude ranges of $M_{w} 3.0-4.0$, years, respectively.

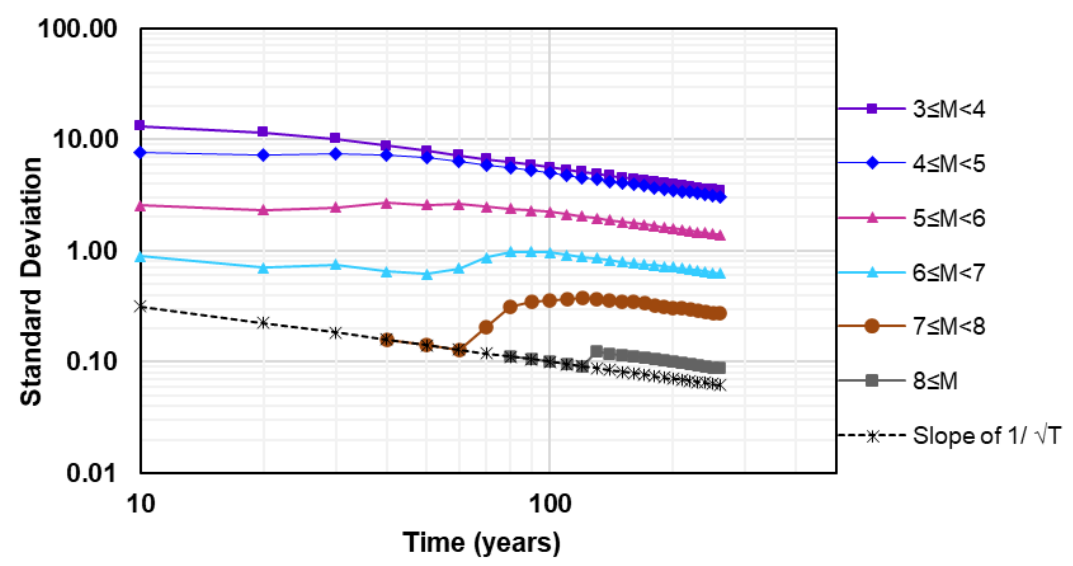

Fig. 5 Completeness of the earthquake catalogue with time 
193 The seismicity of a region can be described by seismic parameters $a$ and $b$, which correlate

194 with the rate of occurrence of an event of a particular size. The distribution of event sizes in a 195 given period is best described by a most widely accepted Gutenberg-Richter recurrence law 196 (Kramer 1996) as given by Eq. 1.

$$
\log (N)=a-b\left(M_{w}\right)
$$

198 Where $N$ represents the number of cumulative events, per year, greater than an event of given 199 moment magnitude; $a$ and $b$ are constants of regression, known as seismic parameters.

200 Based on the completeness study, the earthquake catalogue of the recent 70 years is considered 201 to evaluate recurrence relation for each source zone (Fig. 6). The total number of earthquakes 202 above the magnitude of completeness are 566, 431, 722, 2247, and 871 in the source zones 1 , $2032,3,4$, and 5, respectively. The obtained values of seismic parameters $a$ and $b$ are summarized 204 in Table 2.

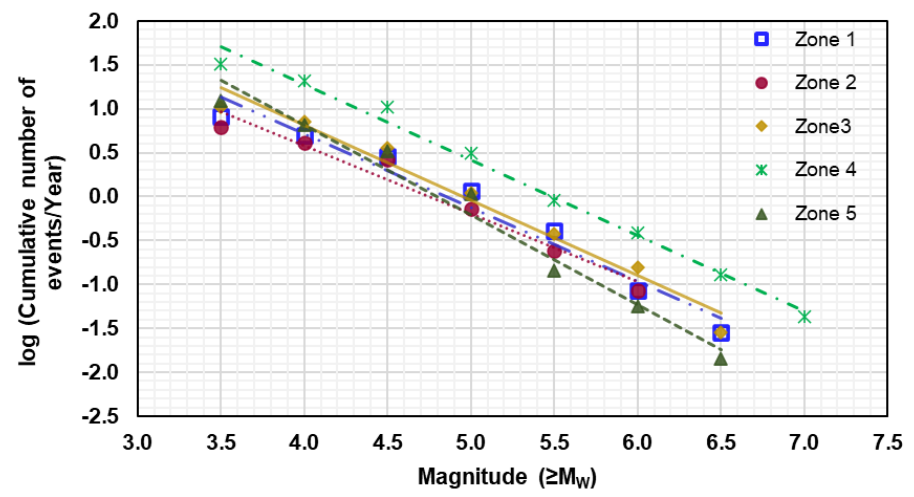

Fig. 6 Gutenberg-Richter relation for each source zone

Table 2 Seismic Parameters and $M_{C}$ values

\begin{tabular}{ccc}
\hline Source & \multicolumn{2}{c}{ Seismic parameters } \\
zones & $M_{C}($ using MAXC) & $a$ \\
\end{tabular}




\begin{tabular}{lllll}
\hline 1 & 3.60 & $4.06 \pm 0.36$ & $0.84 \pm 0.07$ & 0.96 \\
2 & 3.50 & $3.67 \pm 0.36$ & $0.77 \pm 0.07$ & 0.95 \\
3 & 3.40 & $4.23 \pm 0.33$ & $0.85 \pm 0.06$ & 0.96 \\
4 & 3.50 & $4.70 \pm 0.19$ & $0.86 \pm 0.03$ & 0.98 \\
5 & 3.70 & $4.90 \pm 0.37$ & $1.02 \pm 0.07$ & 0.97 \\
\hline
\end{tabular}

208

209 3.1.6 Evaluation of Maximum Magnitude $\left(M_{\max }\right)$

210 The largest possible earthquake, $M_{\max }$, that a seismic source can produce ever is an important 211 input parameter for PSHA. In this study, $M_{\max }$ is evaluated based on the conventional 212 incremental value method, IVM (Gupta 2002; Anbazhagan et al. 2019) and the procedure 213 suggested by Kijiko and Sellevo (1989), typically referred to as KS89. A similar procedure has 214 been used by others as well (Sitharam and Sil 2014).

215 It is based on the doubly truncated G-R relation (Kijiko 2004) as given below.

216

$$
M_{\max }=m_{\max }^{o b s}+\Delta, \text { where } \Delta=\frac{E_{1}\left(n_{2}\right)-E_{1}\left(n_{1}\right)}{\beta \exp \left(-n_{2}\right)}+m_{\min } \exp (-n)
$$

217 Where, $M_{\max }$ is the calculated maximum magnitude, $m_{\max }^{o b s}$ is the observed maximum magnitude 218 associated with each fault, $n$ is the number of events above $M_{C}$ in the region and $m_{\min }$ denotes 219 the minimum magnitude. It should be mentioned here that the KS89 procedure can be applied 220 only when the seismic parameter ' $b$ ' of the region is known.

221 Based on $M_{C}$ value, $m_{\min }$ in the present study is taken as $3.5\left(M_{w}\right) \cdot n_{1}=\frac{n}{1-\exp \left(-\beta\left(m_{\max }-m_{\min }\right)\right.}$ $222, n_{2}=n_{1} \exp \left[-\beta\left(m_{\max }-m_{\min }\right)\right]$, and $E_{1}\left(n_{i}\right)$ is an exponential integral function which can be 
223 approximated as $E_{1}\left(n_{i}\right)=\frac{n_{i}^{2}+a_{1} n_{i}+a_{2}}{n_{i}\left(n_{i}^{2}+b_{1} n_{i}+b_{2}\right)} \exp \left(-n_{i}\right)$, where $a_{1}=2.334733, a_{2}=0.250621, b_{1}$ $224=3.330657$ and $b_{2}=1.681534$ (Abramowitz and Stegun 1970).

225 However, the incremental value method, which is relatively simple and applied by many 226 researchers, $M_{\max }$ is obtained by adding a constant value of 0.5 to $m_{\max }^{\text {obs }}$ value of each seismic 227 source (Gupta 2002; Anbazhagan et al. 2019; Bhuguna and Sil 2020). Values of $M_{\max }$ 228 calculated by both methods are given in Table 3 .

\subsubsection{Deaggregation of Seismic Sources}

230 The recurrence relations for different seismic regions of the study area are evaluated, but it is also essential to assess the seismic activity rate of each fault to proceed further with the PSHA. For this purpose, an approach similar to Raghukanth and Iyenger (2006) and NDMA (2010) is adopted in this study. A conservation property is heuristically used to develop recurrence relations. The number of earthquakes per year with $M_{w} \geq m_{\min }$ i.e., $N\left(m_{\min }=3.5\right)$ in a region is calculated from the G-R relation of that region using Eq. 1. Since all these events are associated with the faults within the region, it should be equal to the sum of the number of

237 earthquakes occurring on individual faults, i.e. $N\left(m_{\min }\right)=\sum_{i=1}^{n} N_{i}\left(m_{\min }\right)$, where $N_{i}\left(m_{\min }\right)$ is the annual frequency of events of $M_{w} \geq m_{\min }$ on the $i^{\text {th }}$ fault in the region, $(i=1,2,3, \ldots, n)$. The annual frequency of events, $N_{i}\left(m_{\min }\right)$ on any fault, depends on the fault length and past seismic

240 activity of the fault. The evaluation of $N_{i}\left(m_{\min }\right)$ involves two basic assumptions: (1) longer 241 faults will have a higher capacity to rupture into smaller segments, and (2) shorter faults may 242 be more active in producing relatively smaller size events. Correspondingly, $N_{i}\left(m_{\min }\right)$ is 243 obtained using the following equation 
245 Where $\alpha_{i}=L_{i} / \sum L_{i}$ is the weighing factor for length of $i^{\text {th }}$ fault $\left(L_{i}\right), \chi_{i}$ is another weighting

246 factor defined as the ratio of the number of earthquakes associated with $i^{\text {th }}$ fault to the total 247 number of earthquakes in the region. In this study, 21 active seismic sources are identified and 248 the detail of each fault in terms of the number of earthquakes associated with it, its length, 249 weighing factors, and the evaluated maximum magnitude, are given in Table 3 . The $b$-value of 250 each fault is considered to be equal to the $b$-value of the region in which the fault is located, 251 and the equation obtained is given below:

$$
N_{i}(m)=N_{i}\left(m_{\min }\right)\left[1-\frac{1-e^{\left\{-\beta\left(m-m_{\min }\right)\right\}}}{1-e^{\left\{-\beta\left(m_{\max }-m_{\min }\right)\right\}}}\right]
$$

253 Where, $m_{\min }$ is the minimum threshold magnitude, $m_{\max }$ is the maximum potential magnitude of the fault $i$, and $\beta=2.303 \mathrm{~b}$. The individual fault level recurrence relations are shown in Figs. 7a-e.

\subsubsection{Ground Motion Prediction Equation (GMPE)}

The knowledge of site-specific attenuation relation is significant for the evaluation of GMP, but due to lack of good quality data, previously developed models for the same or of other regions based on similar tectonic features can be used (Nath and Thingbaijam 2012; Das et al. 2016).

In the present study, six GMPEs are selected (Table 4) and validated through the recorded strong motion data obtained from the NER of India. For this purpose, PGA vs hypocentral distance graphs, shown in Fig. 8a-e, are obtained for different combinations of magnitude and focal depth using the selected GMPEs given in Table 4. The observed PGA values from strong ground motion records for the same magnitude focal depth $\left(M_{w}, h\right)$ combination are also 
plotted, as shown in Fig. 8(a-e). It can be seen that irrespective of the $M_{w}$ and $h$ combinations,

267 ANBA2013 and NATH2012 predicted PGA values are relatively lower than the observed ones.

268 Besides, ATBO2003 is found to have overestimated the PGA for shorter distances and 269 underestimated for longer distances (Fig.8). BAHU2020 also underestimates the PGA, making 270 it the lower bound in few cases. For focal depths greater than $45 \mathrm{~km}$, the PGA values given by 271 the JAIN2000 model lies in the range of observed values, and for lesser depth, the RAMK2020 272 model is found to be more appropriate. Therefore, in the present study, GMPEs RAMK2020

273 (Ramkrishnan et al. 2020) is adopted for seismic source zones with an average focal depth of 274 less than $45 \mathrm{~km}$ and JAIN2000 (Jain et al. 2000) is adopted for seismic source zones with an average focal depth greater than or equal to $45 \mathrm{~km}$, respectively.
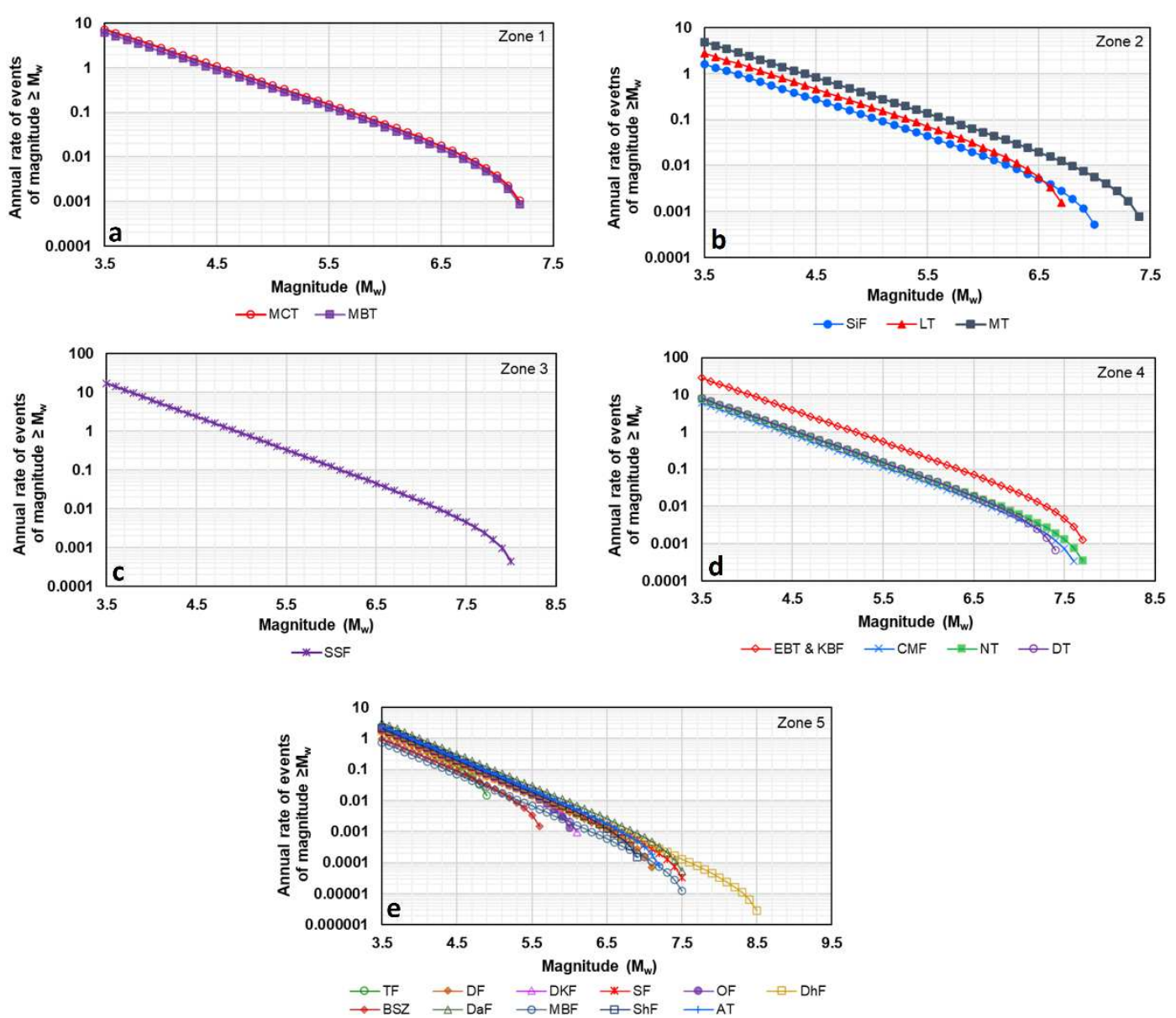

Fig. 7 Fault level recurrence relation for source (a) zone 1, (b) zone 2, (c) zone 3, (d) zone 4, and (e) zone 5 

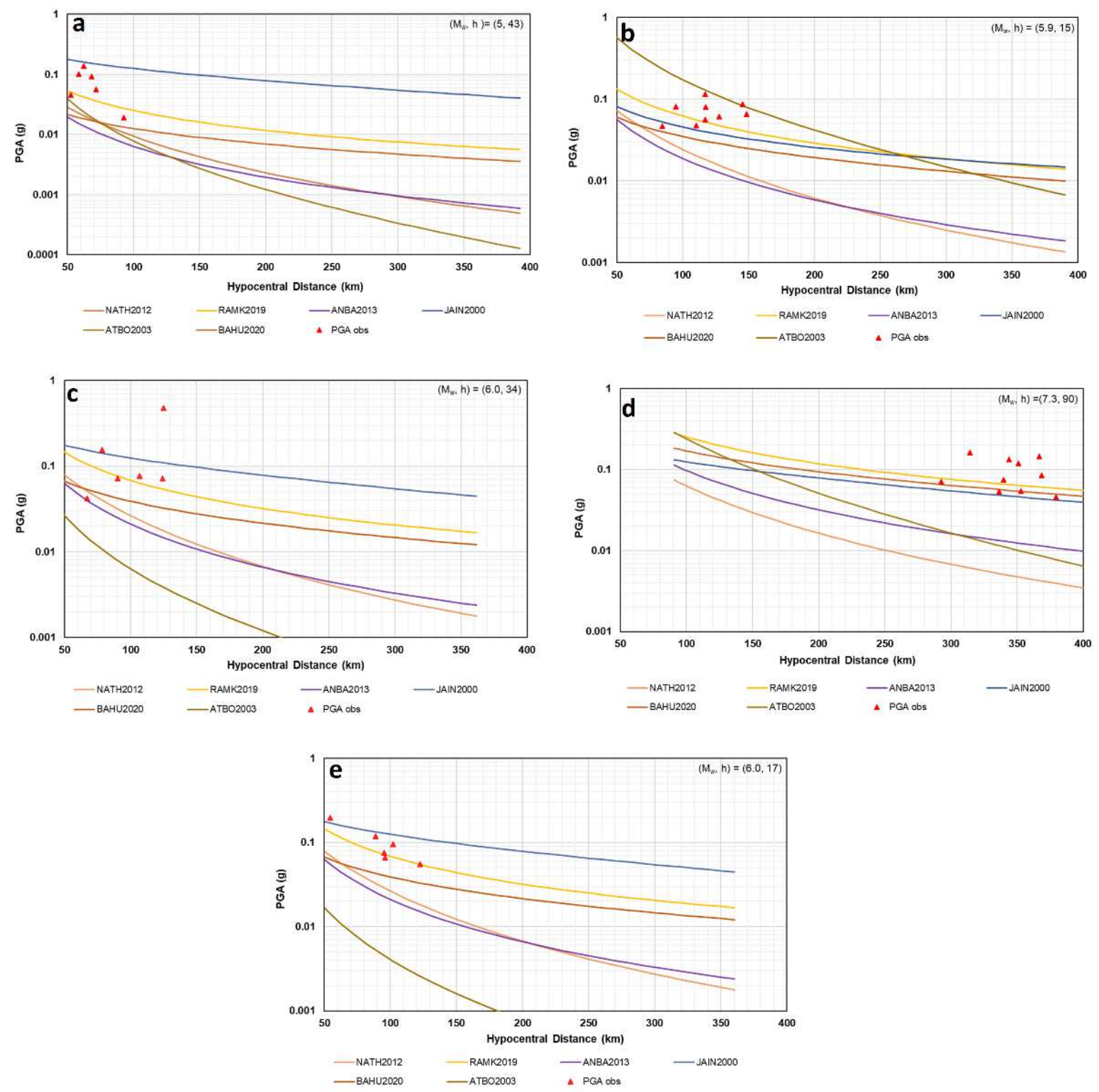

Fig. 8 Comparison of GMPEs with the observed PGA values for a different combination of moment magnitude and hypocentral distance (km): (a) $M_{w} 5.0, h 43$, (b) $M_{w} 5.9, h 15$, (c) $M_{w} 6.0, h 34$, (d) $M_{w} 7.3, h 90$, (e) $M_{w} 6.0, h 1$ 
Table 3 Seismic source zone characterization of the study area

\begin{tabular}{|c|c|c|c|c|c|c|c|c|c|}
\hline \multirow{2}{*}{$\begin{array}{l}\text { Source } \\
\text { zones }\end{array}$} & \multirow{2}{*}{ Fault name } & \multirow{2}{*}{ Fault ID } & \multirow{2}{*}{$\begin{array}{l}\text { Events } \\
\text { associated with } \\
\text { each fault }\end{array}$} & \multirow{2}{*}{$\begin{array}{l}\text { Length } \\
(\mathrm{km})\end{array}$} & \multirow{2}{*}{$\alpha_{i}$} & \multirow{2}{*}{$\chi_{i}$} & \multirow{2}{*}{$\begin{array}{l}\text { Observed } \\
\qquad M_{\max }\end{array}$} & \multicolumn{2}{|c|}{ Calculated $M_{\max }$} \\
\hline & & & & & & & & IVM & $K S 89$ \\
\hline \multirow{2}{*}{1} & $\begin{array}{l}\text { Main Central Thrust } \\
\text { (MCT) }\end{array}$ & 1 & 345 & 631.43 & 0.49 & 0.59 & 6.8 & 7.3 & 6.86 \\
\hline & $\begin{array}{l}\text { Main boundary } \\
\text { Thrust (MBT) }\end{array}$ & 2 & 242 & 654.35 & 0.51 & 0.41 & 6.8 & 7.3 & 6.86 \\
\hline \multirow{3}{*}{2} & Siang Fault (SiF) & 3 & 73 & 87.47 & 0.18 & 0.16 & 6.6 & 7.1 & 6.63 \\
\hline & $\begin{array}{c}\text { Lohit } \\
\text { Thrust (LT) }\end{array}$ & 4 & 180 & 94.79 & 0.20 & 0.40 & 6.3 & 6.8 & 6.32 \\
\hline & Mishmi Thrust (MT) & 5 & 194 & 293.11 & 0.62 & 0.43 & 7 & 7.5 & 7.06 \\
\hline 3 & $\begin{array}{c}\text { Shan-Sagaing } \\
\text { Fault (SSF) }\end{array}$ & 6 & 750 & 704.60 & 1.00 & 1.00 & 7.6 & 8.1 & 7.96 \\
\hline \multirow{4}{*}{4} & $\begin{array}{c}\text { Eastern boundary thrust } \\
\text { and Kabaw Fault (EBT \& } \\
\text { KBF) }\end{array}$ & 7 & 1619 & 821.53 & 0.42 & 0.71 & 7.3 & 7.8 & 7.49 \\
\hline & $\begin{array}{c}\text { Chaurachandpur-Mao } \\
\text { Fault (CMF) }\end{array}$ & 8 & 345 & 174.39 & 0.09 & 0.15 & 7.2 & 7.7 & 7.35 \\
\hline & Naga Thrust (NT) & 9 & 143 & 481.99 & 0.25 & 0.06 & 7.3 & 7.8 & 7.49 \\
\hline & Disang Thrust (DT) & 10 & 180 & 475.78 & 0.24 & 0.08 & 7 & 7.5 & 7.10 \\
\hline
\end{tabular}




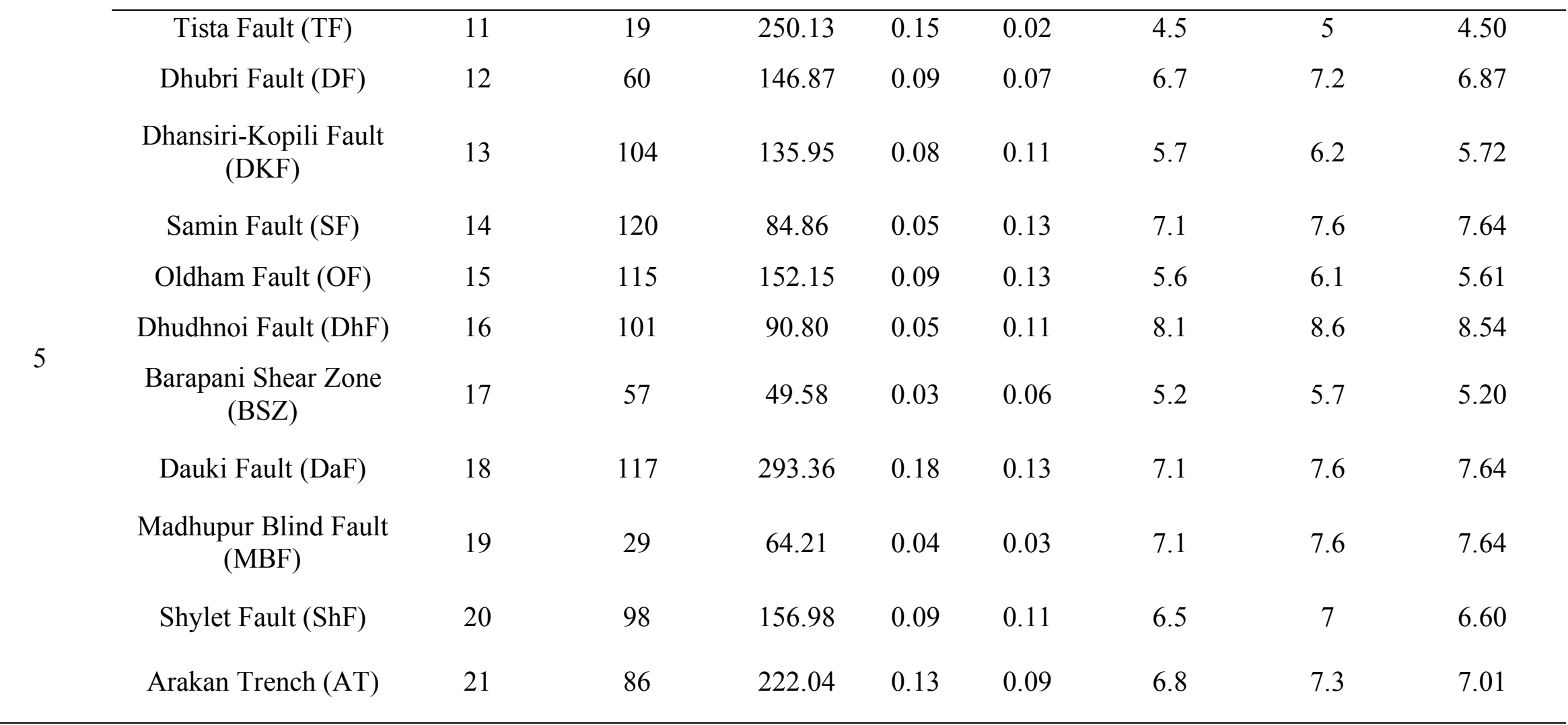

Table 4 List of selected GMPEs

\begin{tabular}{llcc}
\hline S1. No. & GMPE & Abbreviation & Remark \\
\hline 1 & Jain et al. $(2000)$ & For Central- \\
& (a) non-subduction zone: $\ln (P G A)=-3.443+0.706 M-0.8028 \ln (R)$ with $\mathrm{SE}=0.44$ & JAIN2000 & Himalayan \\
& & region & \\
\hline
\end{tabular}


(b) subduction zone: $\ln (P G A)=-0.332+0.00233 R+0.59 \ln (R)$ with $\mathrm{SE}=0.59$

Where PGA in $\mathrm{g}, R$ is the shortest source-to-site distance, and SE is the standard error

$2 \quad$ Atkinson and Boore (2003)

$\log Y=c_{1}+c_{2} M+c_{3} h+c_{4} R-g \cdot \log R+s_{l}\left(c_{5} S_{C}+c_{6} S_{D}+c_{7} S_{E}\right)$

where $Y$ in $\mathrm{cm} / \mathrm{s}^{2}, R=\sqrt{D_{\text {fault }}^{2}+\Delta^{2}}, \quad \Delta=0.00724 \times 10^{(0.507 M)}, \quad c_{1}=2.991, \quad c_{2}=0.03525$, $c_{3}=0.00759, \quad c_{4}=-0.00206, g=10^{(1.2-0.18 M)}, \sigma_{1}=0.20$ (intra-event) and $\sigma_{2}=0.11$ (interevent) for interface events $(\mathrm{h}<50 \mathrm{~km})$ and $c_{1}=-0.04713, c_{2}=0.6909, c_{3}=0.01130$, $c_{4}=-0.00202, g=10^{(0.301-0.01 M)}, \sigma_{1}=0.23$ and $\sigma_{2}=0.14$ for in-slab events $(\mathrm{h}>50 \mathrm{~km})$ and $\left(c_{5}, c_{6}, c_{7}\right)=(0.19,0.24,0.29)$ for all events. $s_{l}$ is frequency-dependent constant. $S_{C}, S_{D}$, and $S_{E}$ are equal to zero for site class B (NEHRP), $V_{S, 30}>760 \mathrm{~m} / \mathrm{s}$.

$3 \quad$ Nath et al. (2012)

$\ln (P)=9.143+0.247 M-0.014(10-M)^{3}-2.67 \ln \left(r_{r u p}+32.9458 \mathrm{e}^{(0.0663 M)}\right)$

NATH200

For the Shillong

where $P=$ PGA $(\mathrm{g}), r_{r u p}=$ fault-rupture distance $(\mathrm{km})$. Standard Deviation $=0.330$. region of $\mathrm{NE}$ India

$4 \quad$ Anbazhagan, Kumar and Sitharam (2013)

$\log (y)=-1.283+0.544 M+b \cdot \log \left(X+e^{(0.381 M)}\right)+\sigma$

where $Y=$ Spectral acceleration (SA) $(\mathrm{g}), X=\sqrt{R^{2}+h^{2}}$, where $R=$ epicentral distance $(\mathrm{km})$,

ANBA2013

For Himalayan region $h=$ focal depth $(\mathrm{km}), b$ is decay parameter $(-1.792)$, and $\sigma=0.283$ (for $0 \mathrm{~s}$ period). 
$\log y=-2.135+0.437 M-1.099 \log \left(X+e^{(-0.080 M)}\right) \pm 0.549$

For Central-

where $\mathrm{y}=\operatorname{PGA}(\mathrm{g}), \mathrm{X}=$ hypocentral distance $(\mathrm{km})$, and $\mathrm{SE}= \pm 0.549$

Himalayan

region

6

Bahuguna and Sil (2020)

$\ln (P G A)=6.680+1.134 M-0.001 R-0.7098 \ln R$

BAHU2020

For Assam

where PGA in $\mathrm{g}, \mathrm{R}=$ hypocentral distance $(\mathrm{km})$ (ranges from $100-400 \mathrm{~km}$ ), and standard region deviation $=0.53$

287 Where, $M$ is moment magnitude 
289

290

291

292

293

294

295

296

297

298

In order to evaluate seismic hazard at bedrock level, using a probabilistic approach, the entire study area was divided into a grid size of $0.2^{\circ} \times 0.2^{\circ}$. Each grid centre is considered as the site of interest at which the seismic hazard in terms of PGA is evaluated by considering all the active seismic sources within a radius of $500 \mathrm{~km}$.

The procedure followed for PSHA assumes that an event within a seismic source follows a stationary Poisson process (Kramer 1996). The probability of GMP, Y, exceeding a specified level, $y$, in a specified period $T$, at a given site is expressed as

$$
P(Y>y)=1-\exp \left(\mu_{y} T\right)
$$

Where, $\mu_{y}$ is the mean annual rate of exceedance as detailed below

$$
\mu_{y}=\sum_{i=1}^{n} N_{i}\left(m_{\min }\right) \iint_{m} P(Y>y \mid m, r) p_{R \mid M}(r \mid m) p_{M}(m) d r d m
$$

In this equation, $n$ is the total number of faults present, $N_{i}\left(m_{\min }\right)$ is the annual frequency of events on an $i^{\text {th }}$ fault having $m \geq m_{\min }, p_{M}(m)$ is the probability density function (PDF) 301 corresponding to the magnitude, $p_{R \mid M}(r \mid m)$ is the conditional PDF corresponding to hypocentral distance $(r)$, and $P(Y>y \mid m, r)$ is the probability of exceedance of GMP, $Y$, over $y$, for an event of magnitude $m$ occurring at a distance $r$ from the site. $\mu_{y}$ incorporates the temporal, spatial, and magnitude uncertainty of a future event and ground motion uncertainty produced by them at the site. Eq. 7 shows the summation of individual contributions of 21 faults $(i=1,2,3 \ldots 21)$ for the assessment of hazard at each site to obtain the annual exceedance of PGA. All the above-mentioned calculations are performed using MATLAB.

The typical PDF of magnitude and distance is shown in Fig. 9. To produce the hazard curve considering all the sources, $\mu_{y}$ of a particular site of interest are summed up and plotted against 

curves, the PGA value for $10 \%$ probability of exceedance over 50 and 100 years of return period and $2 \%$ probability of exceedance over 50 years of return period are obtained.

313 Correspondingly, thematic maps, at each site of interest, are produced using ArcGIS.
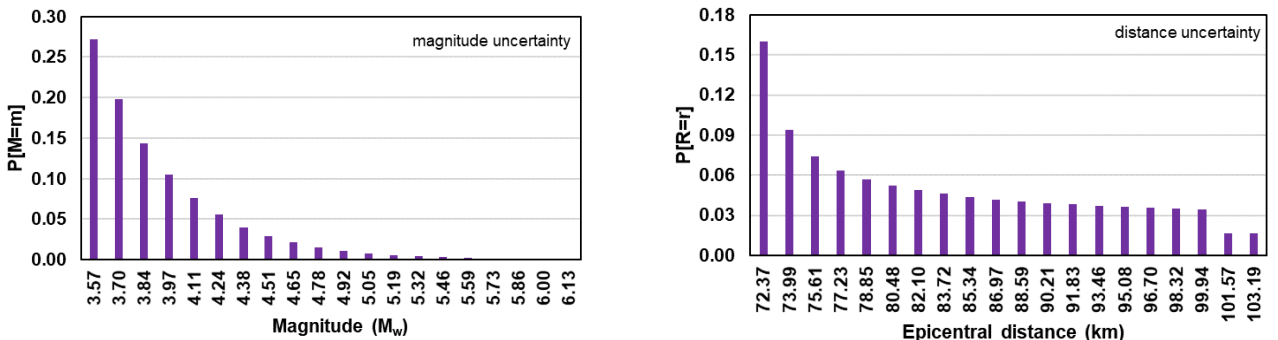

Fig. 9 Probability density function (PDF) for (a) magnitude uncertainty, (b) epicentral distance uncertainty

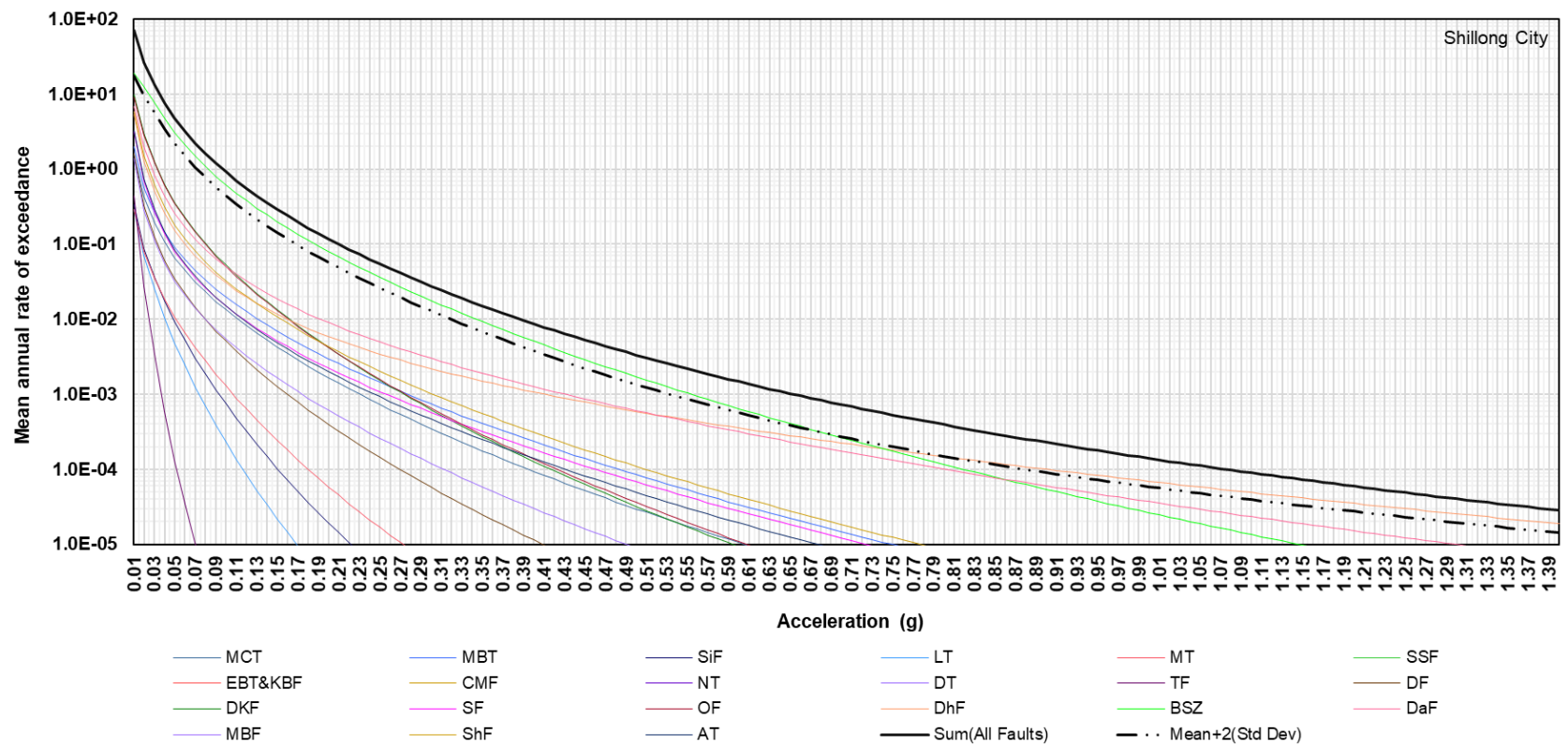

Fig. 10 Seismic hazard curves (Shillong city)

\subsection{Social Vulnerability Assessment}

In the present study, the HoP model is adopted for assessing the social vulnerability (SV) of different districts of SSS. The HoP model (Cutter 1996) tries to combine social and biophysical vulnerability to produce overall place vulnerability (Cutter et al. 2003). This model has been used in many social vulnerability studies worldwide (Ge et al. 2013; Frigerio et al. 2016; 
324 Agrawal et al. 2021). Details of the methodology adopted for the social vulnerability analysis,

325 SVA are presented and discussed in the following subsections.

326

\subsubsection{Data Acquisition}

327 The social vulnerability assessment depends on the indicators like population, age, gender,

328 literacy, employment status, stock of built structures, etc. (Cutter et al. 2003; Wood et al. 2010;

329 Depietri 2013, 2020; Kolathayar 2021; Siagian et al. 2014; Fatemi et al. 2017). For the present

330 study, data regarding these indicators comprising 54 variables were collected, at the district

331 level, from India's 15th housing and population census (Census 2011). Multi-collinearity

332 analysis was performed on the collected set of variables, and a subset of 33 variables was

333 retained and used to create indices for SV in Table 5.

334 Table 5 List of common social vulnerability indicators and their variables.

\begin{tabular}{|c|c|c|c|}
\hline S1. No. & Indicator & & Variables \\
\hline 1 & \multirow{4}{*}{$\begin{array}{l}\text { Population } \\
\text { composition }\end{array}$} & P01 & Population density \\
\hline 2 & & $\mathrm{P} 02$ & Male (\%) \\
\hline 3 & & $\mathrm{P} 03$ & Female $(\%)$ \\
\hline 4 & & P04 & Population belongs to socially backward class (\%) \\
\hline 6 & \multirow{3}{*}{ Age } & Age01 & Age less than $07(\%)$ \\
\hline 7 & & Age02 & Age group of 07 to $60(\%)$ \\
\hline 8 & & Age03 & Above the age of $60(\%)$ \\
\hline 9 & \multirow{4}{*}{ Literacy } & L01 & Effective literacy rate \\
\hline 10 & & L02 & Illiterate $(\%)$ \\
\hline 11 & & L03 & Illiterate female (\%) \\
\hline 12 & & EO01 & Population belongs to $\mathrm{MW}^{1}$ class (\%) \\
\hline 13 & \multirow{11}{*}{$\begin{array}{c}\text { Employment } \\
\text { status and } \\
\text { occupation }\end{array}$} & EO02 & Female population belongs to $\mathrm{MW}^{1}$ class $(\%)$ \\
\hline 14 & & EO03 & Population belongs to the $\mathrm{OMW}^{2}$ class $(\%)$ \\
\hline 15 & & EO04 & Female population belongs to the $\mathrm{OMW}^{2}$ class $(\%)$ \\
\hline 16 & & EO05 & Population belongs to $\mathrm{MrW}^{3}$ class $(\%)$ \\
\hline 17 & & EO06 & Female population belongs to $\mathrm{MrW}^{3}$ class (\%) \\
\hline 18 & & EO07 & Population belongs to the $\mathrm{OMrW}^{4}$ class $(\%)$ \\
\hline 19 & & EO08 & Female population belongs to the $\mathrm{OMrW}^{4}$ class $(\%)$ \\
\hline 20 & & EO09 & Non-permanent employment (\%) \\
\hline 21 & & EO10 & Female population with non-permanent employment (\%) \\
\hline 22 & & EO11 & Non-working population $(\%)$ \\
\hline 23 & & EO12 & Non-working female population $(\%)$ \\
\hline 24 & \multirow{2}{*}{$\begin{array}{l}\text { Building } \\
\text { material }\end{array}$} & BM01 & With brick or stone roof $(\%)$ \\
\hline 25 & & BM02 & With kutcha roof $(\%)$ \\
\hline
\end{tabular}


26

27

28

29

30

31

32

BM03 With kutcha wall (\%)

BM04 With kutcha floor (\%)

House $\quad \mathrm{HC} 01$ Residential houses in dilapidated condition (\%)

condition $\mathrm{HC} 02$

Residential cum other houses in dilapidated condition (\%)

Family size

$\mathrm{HH} 01$

HH02

Houses with 4-5 households (\%)

Houses with 6 or more households (\%)

A01

Amenities

Houses with no electricity and have dependence upon

kerosene or other oil as a source of light (\%)

A02

Houses with no water source within or near the premises of the house $(\%)$

${ }^{1} \mathrm{MW}$ : Main Workers; Workers who worked for more than six months in the reference period

OW: Other Workers; Workers other than cultivators, agricultural laborers, or household workers. eg. Government servants, municipal employees, teachers, bankers, trade and commerce, etc.

${ }^{2} \mathrm{OMW}$ : Other Main Workers; Main workers falling under OW

${ }^{3} \mathrm{MrW}$ : Marginal Workers; Workers who worked for less than six months

${ }^{4} \mathrm{OMrW}$ : Other Marginal Workers; Marginal worker falling under OW

\subsubsection{Evaluation of SVI}

The social vulnerability index (SVI) is evaluated using the steps summarized below.

1. Variables of vulnerability indicators are selected, and high multi-collinearity among the variables is checked.

2. After eliminating the highly correlated variables, the remaining set of variables are checked for sample adequacy using KMO (Kaiser-Meyer-Olkin) and Bartlett's test. If the KMO value $>0.7$ and Bartlett's test of sphericity shows a significance value $<0.05$, the dataset is considered adequate, and the factor analysis (FA) is employed (Sharma 1996).

3. The principal component analysis (PCA) is utilized for factor extraction. Factors with eigenvalue $>1.0$ are extracted and rotated using the varimax method of factor rotation with Kaiser normalization, as shown in Table 6. The extracted factors are confirmed by tracking the changes in the slop of the scree plot shown in Fig. 11.

4. The factor score is generated for extracted factors using the Anderson-Rubin method. All these steps are performed using IBM SPSS (v 26). 
5. The generated scores are aggregated (Ge et al. 2013), and a composite index (SVI) is generated using the weightage factor $\left(w_{i}\right)$, calculated based on the percentage variance explained by factor $i\left(v_{i}\right)$ out of the total variance explained by all the factors $\left(v_{t}\right)$ as in Eq. 8. Then the composite SVI is obtained by using Eq. 9.

$$
w_{i}=v_{i} / v_{t}
$$

$$
S V I=\sum_{i=1}^{n_{f}} w_{i} \times \text { Factor } \mathrm{i} \quad \text {, where } n_{f} \text { is the number of factors }
$$

6. The SVI scores are classified into five vulnerability classes, and thematic maps are created to display the spatial distribution of social vulnerability using ArcGIS.

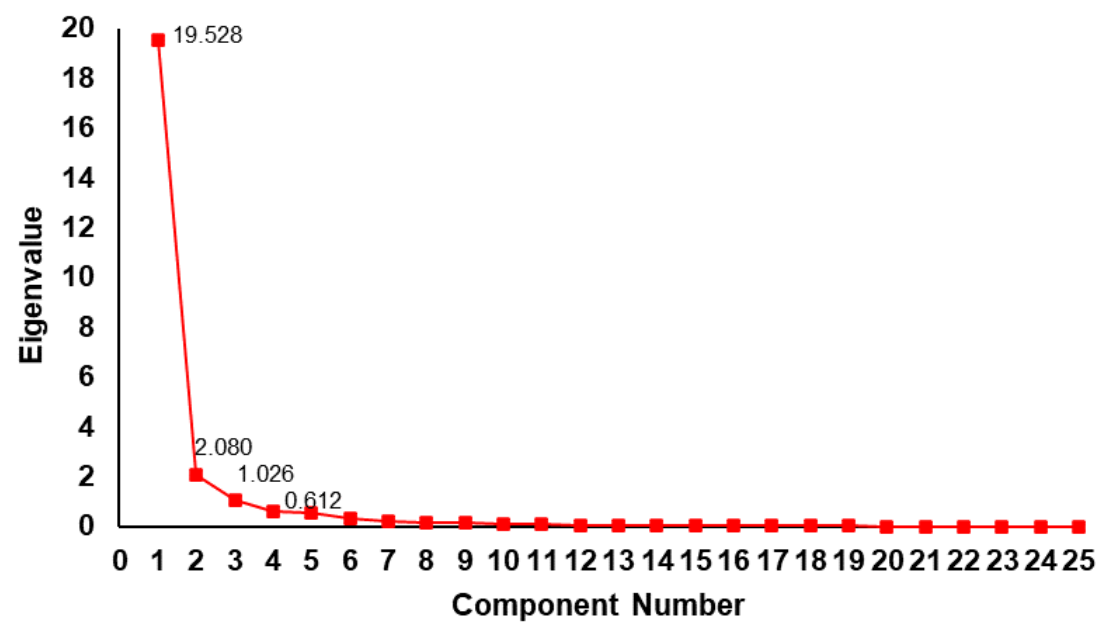

Fig. 11 Scree plot

\begin{tabular}{|c|c|c|c|c|}
\hline Factor & Extracted variables & Eigenvalue & $\begin{array}{c}\text { Variance } \\
\text { explained (\%) }\end{array}$ & $\begin{array}{l}\text { Weightage } \\
\text { factor }\left(w_{i}\right)\end{array}$ \\
\hline 1 & $\begin{array}{l}\mathrm{HC} 01, \mathrm{~A} 01, \mathrm{~L} 02, \mathrm{P} 02, \mathrm{~L} 03, \\
\text { Age01, HC02, BM03, EO12, } \\
\mathrm{HH} 02, \mathrm{EO} 11, \mathrm{BM} 02 \text {, and A02 }\end{array}$ & 19.528 & 37.87 & 0.42 \\
\hline 2 & $\begin{array}{c}\mathrm{BM} 01, \mathrm{EO} 03, \mathrm{EO} 07, \mathrm{HH} 01, \\
\text { Age03, and P04 }\end{array}$ & 2.080 & 27.35 & 0.30 \\
\hline
\end{tabular}

Table 6 Selected variables based on PCA 


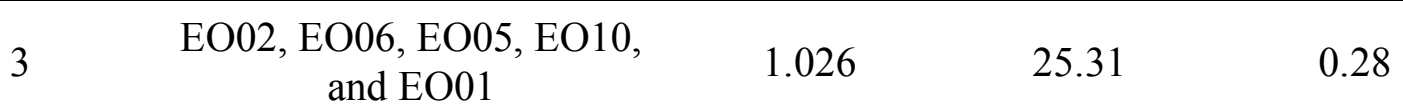

367

\subsubsection{Spatial Cluster Analysis}

369

370

371

372

373

374

375

A global spatial autocorrelation is performed to analyze the autocorrelation of the dataset throughout the study area, and Global Moran's I value that ranges from -1 to 1, was obtained (Karuppusamy et al. 2021). A spatial statistical tool for hotspot analysis (Getis-Ord Gi*) in ArcGIS is employed to identify the spatial clusters within a specific area (Brandt et al. 2020). The hotspots are located based on the values of statistically significant $z$ for 99,95 , and $90 \%$ confidence levels. Typically the hotspots exhibit higher $z$ scores and lower $p$ scores (Al-Dogom et al. 2018). In this analysis, a zone of indifference is selected for the spatial relationship conceptualization, and a threshold distance of $71542 \mathrm{~m}$ is used. False discovery rate (FDR) correction is applied to identify spatial clusters at the local level better.

\subsection{Exposure Assessment}

For the seismic exposure assessment, the PGA values for the 475-year return period are classified into five hazard classes (Fig. 17a) and integrated with the SVI. The resulting seismic exposure map (Fig. 17b) was analyzed using a risk matrix) (Derakhshan et al. 2020) as shown in Fig 12.

\begin{tabular}{|c|c|c|c|c|c|c|}
\hline & & \multicolumn{5}{|c|}{ Hazard Classes } \\
\hline & & $\begin{array}{c}\text { Very Low } \\
\text { (1) }\end{array}$ & $\begin{array}{l}\text { Low } \\
(2)\end{array}$ & $\begin{array}{c}\text { Moderate } \\
\text { (3) }\end{array}$ & $\begin{array}{c}\text { High } \\
(4)\end{array}$ & $\begin{array}{l}\text { Very High } \\
\text { (5) }\end{array}$ \\
\hline \multirow{5}{*}{ 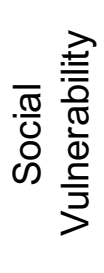 } & Very low (1) & 1 & 2 & 3 & 4 & 5 \\
\hline & $\operatorname{Low}(2)$ & 2 & 4 & 6 & 8 & 10 \\
\hline & Moderate(3) & 3 & 6 & 9 & 12 & 15 \\
\hline & High(4) & 4 & 8 & 12 & 16 & 20 \\
\hline & Very High (5) & 5 & 10 & 15 & 20 & 25 \\
\hline \multicolumn{2}{|c|}{ Risk Classes } & Very Low & Low & Moderate & High & Very High \\
\hline
\end{tabular}

Fig. 12 Risk matrix 


\section{Results and Discussion}

In the present study, the results of PSHA are presented in terms of PGA at bedrock level, which is obtained from the hazard curve i.e. PGA vs. mean annual rate of exceedance. The SVI was generated by applying the FA and PCA as the factor extraction method. The results of SHA and SVI were then integrated to prepare the exposure maps for the study region.

From Table 7, it can be seen that the seismic parameters, $a$ and $b$, obtained from the present study, compare well with the values reported by others (NDMA 2010; Sharma and Malik 2006; and Bahuguna and Sil 2020). For SSS in the present study, the PGA values corresponding to return periods of 475, 950, and 2475 years, obtained using GMPE (Ramkrishnan et al. 2020, Jain et al. 2000), are in the range of $0.14-0.69 \mathrm{~g}, 0.17-0.86 \mathrm{~g}$, and $0.22-0.93 \mathrm{~g}$, respectively. The calculated PGA values for some selected cities in the region are compared with those from previous studies as shown in Table 8 . It can be seen that the calculated PGA values in the present study are relatively lower than those reported by Nath and Thingbaijam (2012). In the case of cities like Aizwal, Imphal, and Kohima, the PGA values for low probability of exceedance (return period $=475$ years) are comparable with that of NDMA 2010 (Table 8). In contrast, at Aizwal and Imphal, the calculated PGA values are less than that reported by Sharma and Malik (2006) and higher than that by Sil et al. (2013). At Guwahati and Shillong, the calculated PGA values are in a higher range than that reported by Ghione et al. (2021). Such variations are attributed to the selection of different seismic source zones and different ground attenuation models, which can be considered as a limitation of the PSHA method.

The spatial distributions of PGA at the bedrock level for SSS are shown in Fig. 13a-c. The northern and western part of the region shows higher PGA values. This is due to the influence of MFT, MCT, and Dauki Fault. Similarly, the area in the vicinity of Mishimi Thrust and Lohit 
Thrust also shows higher PGA values. Therefore, this region can be classified as a high seismic

409 hazard zone.

410 Table 7 Comparison of estimated seismic parameters with previously reported values

\begin{tabular}{|c|c|c|c|c|c|}
\hline Parameter & $\begin{array}{c}\text { Das, Sharma, } \\
\text { and Wason } \\
(2016)\end{array}$ & NDMA (2010) & $\begin{array}{c}\text { Sharma and } \\
\text { Malik } \\
(2006) \\
\end{array}$ & $\begin{array}{c}\text { Bahuguna } \\
\text { and Sil } \\
(2020) \\
\end{array}$ & $\begin{array}{l}\text { Present } \\
\text { study }\end{array}$ \\
\hline$a$ & $1.68-5.76$ & - & - & $0.15-4.52$ & $3.67-4.89$ \\
\hline$b$ & $0.43-1.07$ & $\begin{array}{l}\text { Zone4: } 0.71 \pm 0.04 \\
\text { Zone5: } 0.66 \pm 0.03 \\
\text { Zone7: } 0.67 \pm 0.08 \\
\text { Zone8: } 0.73 \pm 0.04 \\
\text { Zone10: } 0.80 \pm 0.02 \\
\text { Zone11: } 0.66 \pm 0.04\end{array}$ & $0.42-1.04$ & $0.18-0.9$ & $0.77-1.02$ \\
\hline$M_{c}$ & $3.6-4.6$ & - & - & - & $3.4-3.7$ \\
\hline
\end{tabular}

412 Table 8 Comparison of estimated PGA values obtained for important cities with previously 413 reported values

\section{PGA $(g)$}

\begin{tabular}{|c|c|c|c|c|c|}
\hline $\begin{array}{l}\text { Sl. } \\
\text { No. }\end{array}$ & City & $\begin{array}{l}\text { Present } \\
\text { Study }\end{array}$ & $\begin{array}{l}\text { NDMA } \\
(2010)^{\dagger}\end{array}$ & $\begin{array}{l}\text { Nath and Thingbaijam } \\
\qquad(2012)^{\ddagger}\end{array}$ & Other studies \\
\hline 1 & Guwahati & $0.60-0.85$ & $0.23-0.40$ & $0.66-1.40$ & $\begin{array}{c}0.35 \text { (Ghione, Poggi } \\
\text { and } \\
\text { Lindholm 2021)*; 0.46- } \\
0.92(\text { Bahuguna and } \\
\text { Sil 2020) }{ }^{\dagger},\end{array}$ \\
\hline 2 & Agartala & $0.32-0.47$ & $0.12-0.20$ & $0.25-0.60$ & $\begin{array}{c}0.22 \text { (Das, Sharma and } \\
\text { Wason 2016); 0.11- } \\
0.20 \text { (Sil, Sitharam and } \\
\text { Kolathayar 2013)* } \\
0.3 \text { (Sharma and }\end{array}$ \\
\hline 3 & Aizawl & $0.20-0.32$ & $0.22-0.45$ & $0.45-1.20$ & $\begin{array}{c}\text { Malik 2006)*; 0.1-0.17 } \\
\text { (Sil, Sitharam and } \\
\text { Kolathayar 2013) } \\
\text { 0.4(Sharma and }\end{array}$ \\
\hline 4 & Imphal & $0.28-0.42$ & $0.30-0.55$ & $0.70-1.40$ & $\begin{array}{c}\text { Malik 2006); } 0.18-0.8 \\
(\text { Pallav et al. 2012) }\end{array}$ \\
\hline 5 & Shillong & $0.61-0.83$ & $0.25-0.45$ & $0.72-1.30$ & $\begin{array}{c}0.55 \text { (Ghione, Poggi } \\
\text { and Lindholm 2021) }\end{array}$ \\
\hline
\end{tabular}


0.44 (Sharma and

$6 \quad$ Itanagar $\quad 0.55-0.88 \quad 0.28-0.45 \quad 0.70-1.20$

Malik 2006) ${ }^{*} ; 0.18$

(Das, Sharma and

Wason 2016) ${ }^{*}$

0.5 (Sharma

$7 \quad$ Kohima $\quad 0.25-0.40 \quad 0.25-0.55$

$0.60-1.30$

and Malik) ${ }^{*}$; 0.15(Das, Sharma and

Wason 2016)*

414

For return period of $* 475$ years; $\$ 475-2475$ years; $\uparrow 475-4950$ years

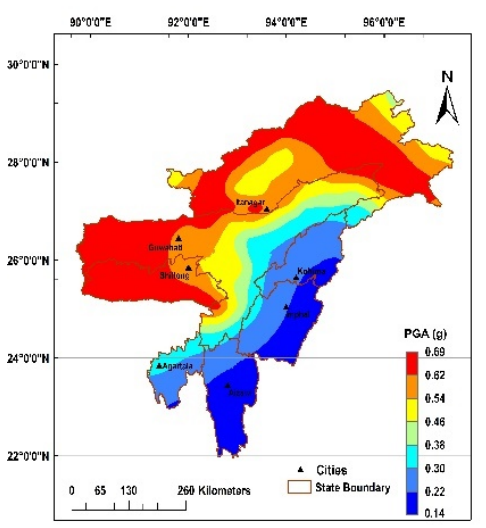

(a)

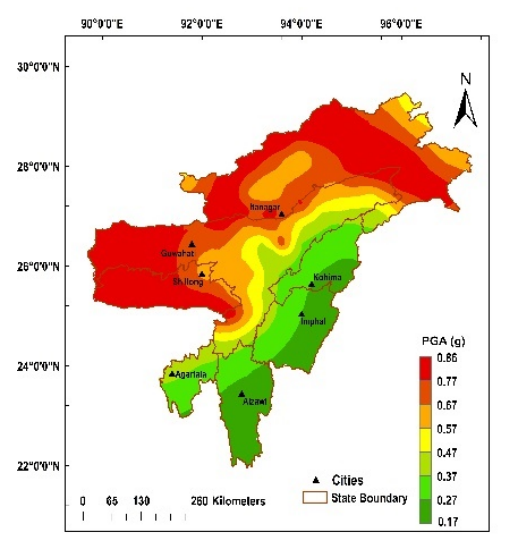

(b)

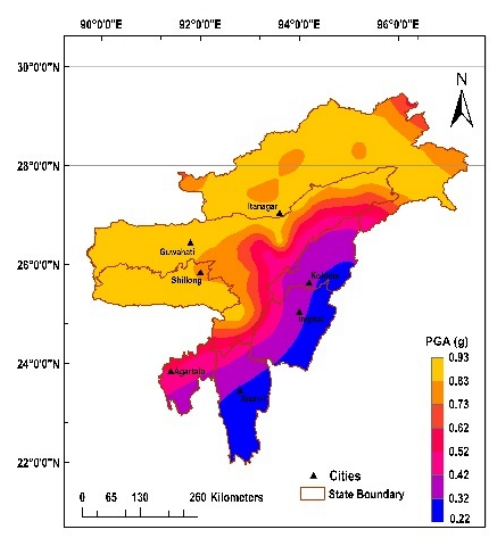

(c)

Fig. 13 Spatial distribution of PGA at the bedrock level for a return period of (a) 475 years,

(b) 950 years, and (c) 2475 years

419 The SVI for the study area is developed considering three significant factors that are obtained by FA. Based on PCA of 33 variables, using Kaiser criterion of factor retention, three

421 significant factors comprised of 24 variables with eigenvalues $>1.0$ are retained. The KMO

422 value of $0.897(>0.7)$ and a significant value of $0(<0.05)$ in Bartlett's test are obtained that 423 indicates sufficient data adequacy for statistical analysis (FA and PCA). The selection of 424 factors is also confirmed by observing the change in slope of the scree plot (Fig. 11). These 425 three factors cumulatively explain the 90.534 percent variance among the datasets. The 426 descriptive statistic of each factor is given in Table 6.

427 The variable composition of factor 1 indicates the living condition and socioeconomic status of the study region. The spatial distribution of vulnerability in terms of factor 1 is shown in

429 Fig. 14a. The districts of Assam and Tripura, having a high percentage of illiterate population, 430 with poor living conditions, fall under the high to very high vulnerable class. Hence, it can be 
said that communities with high illiteracy rates and poor living conditions are less resilient and

432 thereby more vulnerable to seismic disasters. Similar observations have been made by

433 (Frigerio et al. 2016). Factor 2 comprises six variables, governed by building material, aged

434 population, and period of employment. Based on these indices it is observed that the region of

435 Tripura, upper Assam, and Barak valley have a poor quality of built structures, low employment rate, and a high population of old aged people (Fig 14b). All these factors tend to

437 enhance the vulnerability of a region and decrease the society's resilience and coping capacity 438 in case of a disastrous event happening. Factor 3 represents the type of employment and 439 percentage of the female population involved in agriculture and other related activities (Fig. 440 14c). The Seven Sister States of India with a primary focus on agriculture is relatively less 441 urbanized. Agriculture and small-scale household industries are low-paying jobs, and the 442 female population of this region is found to be mainly involved in it. After the disaster, the non-permanent marginal workers having relatively low-paying jobs, are more likely to lose

444 their jobs due to disruption in daily activities and businesses (Morrow 1999). The spatial 445 distribution of Factor 3 shows that the districts of Assam, Meghalaya, Mizoram, and Manipur, 446 having a high percentage of the population dependent on agriculture and small-scale industries, 447 are under a highly vulnerable class.

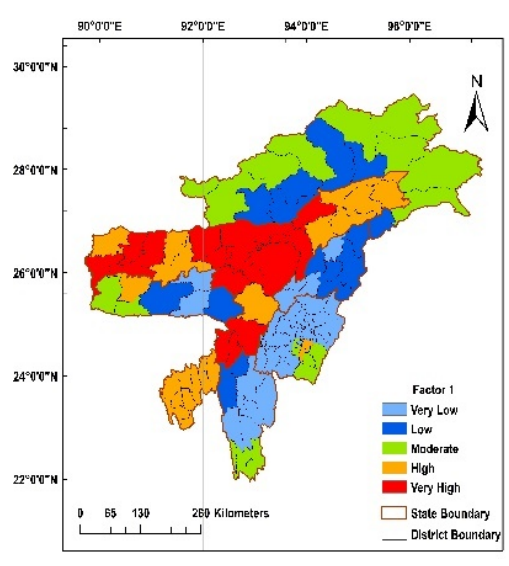

(a)

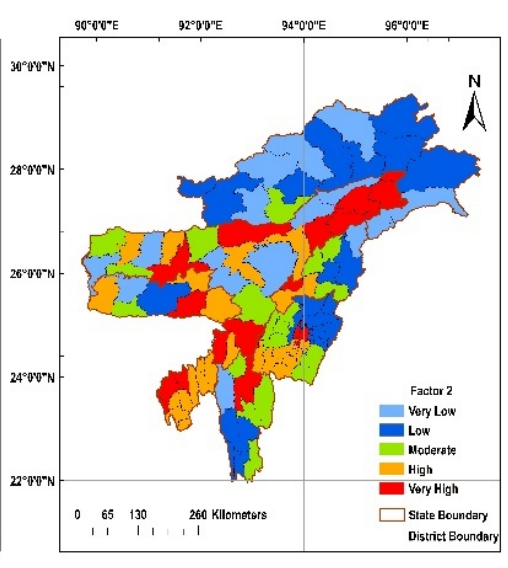

(b)

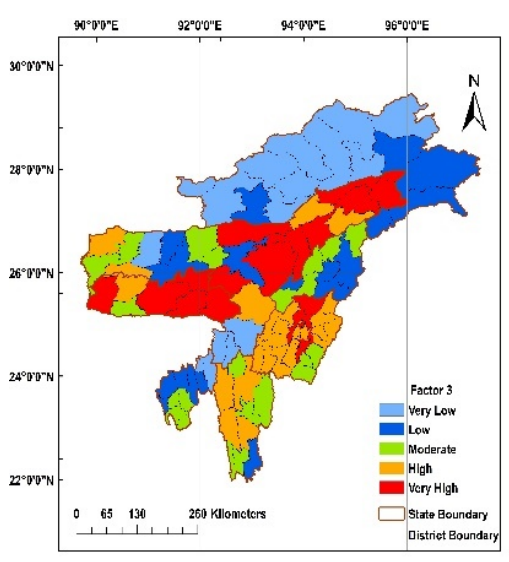

(c) 
451 Fig. 15 shows the spatial distribution of the overall social vulnerability at the district level. It

452 reveals that most districts covering an area of $66.15 \%$ of the study area are under low to 453 moderate SVI class, whereas another $14.56 \%$ area is under high vulnerability and $19.29 \%$ of 454 the area is prone to very high vulnerability. Twenty-one districts of Assam fall under high and 455 very high vulnerable classes, and all districts of Tripura are under high vulnerable classes. 456 These two states share the highest percentage of the population in the study region (i.e., $69.41 \%$ 457 for Assam and $8.01 \%$ for Tripura). With a population density of 439.43 per sq. $\mathrm{km}$ in Assam 458 and 389.11 per sq. $\mathrm{km}$ in Tripura and according to the 2011 census data (Fig. 1), $40 \%$ 459 population of these districts are illiterate, and about $83 \%$ of houses are made of weak building 460 materials are of poor quality. These districts also lack basic amenities like the availability of 461 drinking water, electricity, etc. These factors justify the very high social vulnerability of these 462 districts.

463 The spatial cluster analysis given in Fig. 16a represents hotspot and cold spot analysis. Fig. 16b 464 depicts an overlay of the spatial distribution of the social vulnerability index with hotspots and 465 cold spots. It is observed that high social vulnerability patterns are located in central Assam and its adjoining neighboring areas, and $17.14 \%$ of the total study area emerges as a hot spot with an average SVI score of 0.329 . The cold spots are mainly predominant in Nagaland and the northern part of Arunachal Pradesh, spread over about $8.58 \%$ of the study area, with an average SVI score of 0.177 . With an average SVI score of 0.208 , the remaining area is regarded as non-significant areas in terms of the hotspot and cold spot analysis, and those are the northwestern and southern parts of the study area. 


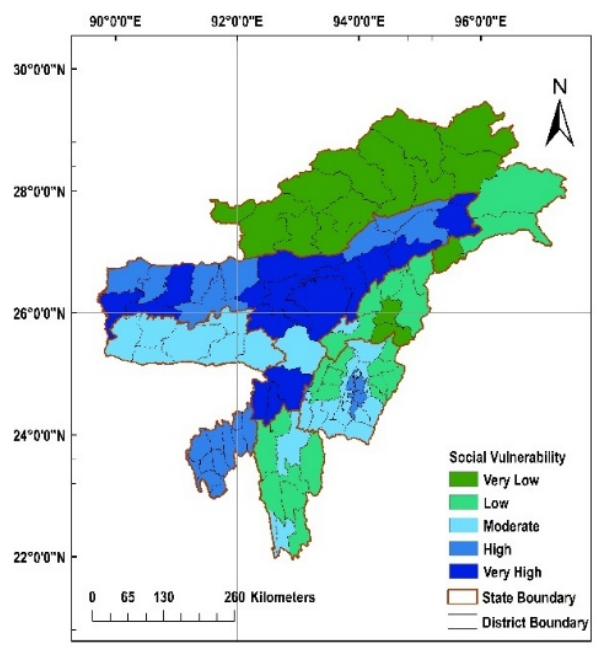

Fig. 15 Spatial distribution of social vulnerability index

474

475

477

478

479

480

481

482

483

484

485
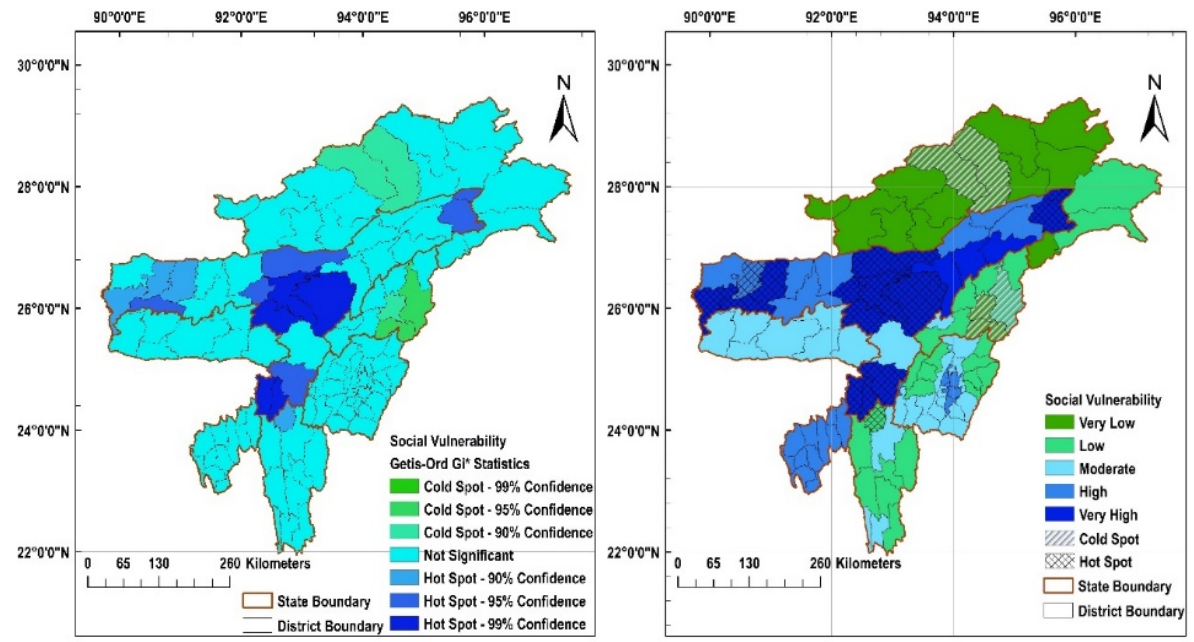

Fig. 16 (a) cluster showing hotspot and cold spot; (b) overlay of a hotspot and cold spot with SVI

Finally, the seismic hazard map (Fig 17a) is integrated with the social vulnerability map (Fig 15), and the exposure map of the study area is prepared and analyzed using the risk matrix in Fig. 12. Fig. 17b shows the spatial distribution of exposure to seismic hazards for the NER of India. The results indicate that 3.33\%, 38.21\%, 29.94\%, $14.59 \%$, and $13.92 \%$ of the total study area falls under very low, low, moderate, high, and very high seismic exposure classes, respectively. The districts of Arunachal Pradesh, Nagaland, and Mizoram mostly fall under very low to moderate seismic exposure classes. Low to moderate seismic exposure zones are found for the districts of Manipur and Tripura. In contrast, the districts of Assam and Meghalaya shows high to very high seismic exposure class. 
486

487

488

489

490

491

492

493

494

495

496

497

498

499

500

501

502

503

504

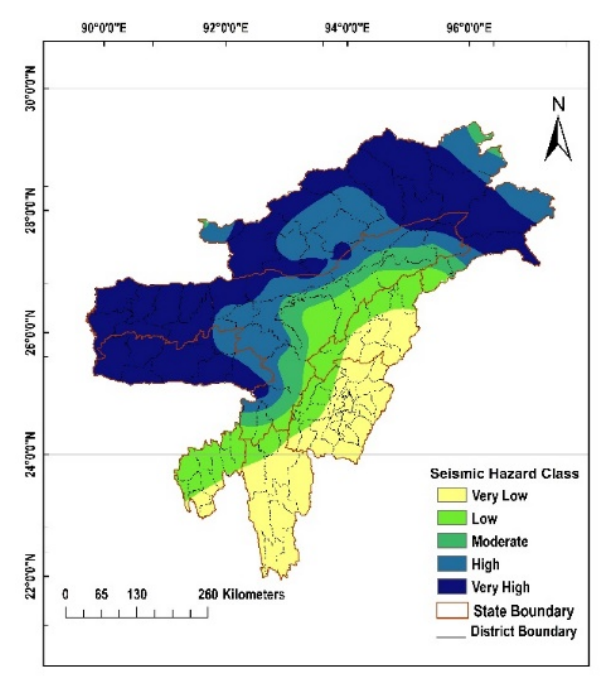

(a)

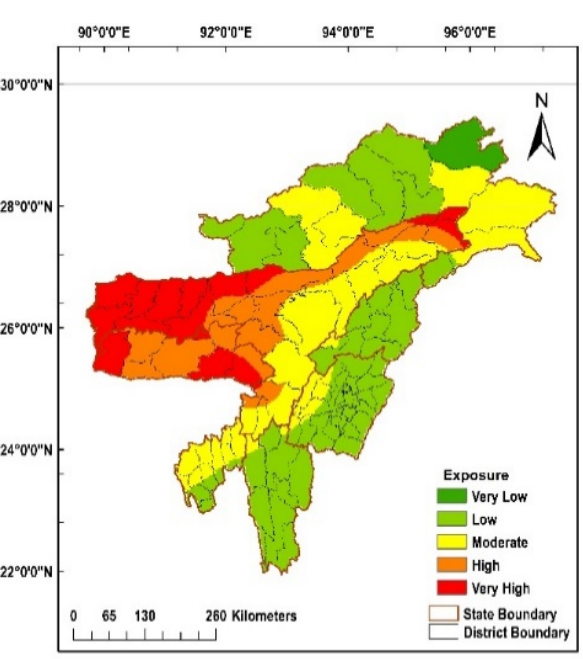

(b)

Fig. 17 (a) seismic hazard class; (b) exposure

\section{Conclusions}

In the present study, updated seismic hazard maps in terms of PGA for the return periods of 475, 950, and 2475 years are generated using the PSHA approach. Correspondingly the PGA values at bedrock level are found to be in the range of $0.14-0.69 \mathrm{~g}, 0.17-0.86 \mathrm{~g}$, and $0.22-0.93 \mathrm{~g}$, respectively. The states of Meghalaya, Assam, and Arunachal Pradesh exhibit relatively higher PGA values, which is attributed to the dominance of the MFT, Dauki fault, and Mishimi thrust zone. The SVI map is generated using FA and PCA to assess the social vulnerability and exposure to seismic hazards. Based on PCA, three factors consisting of 24 variables are retained, which explains the $90.53 \%$ variance among the datasets. Subsequently, the SVI is integrated with the seismic hazard map and an exposure map of the study area is developed.

The spatial distribution of SVI shows that 21 districts covering $91.43 \%$ area of Assam and the entire Tripura state are highly vulnerable. The spatial cluster analysis illustrates high social vulnerability patterns in central Assam and some parts of Meghalaya, Mizoram, Manipur, and Arunachal Pradesh. $17.14 \%$ of the study area, having an average SVI score of 0.329 , is identified as hotspots. The exposure map shows that more than $50 \%$ of the total study area falls under moderate to very high exposure class. The present study provides a reliable tool for 
identifying the most socially vulnerable and critically exposed areas of one of the most seismically active regions of the world, i.e. NER of India. The findings from the present study can be of help in sustainable disaster mitigation planning leading to achieving sustainable development goals and targets. The presented exposure map can help the state authorities and local bodies in preparing for disaster risk reduction, develop mitigation strategies, and emergency planning. The study has some inherent limitations which are due to the lack of realtime socio-economic data. Therefore further research considering geotechnical, geological data, and temporal relationships among the various socioeconomic variables and various

513 hazards, is necessary.

\section{Declaration of interests}

The authors declare that they have no known competing financial interests or non-financial interests or personal relationships that are directly or indirectly related to the work submitted

517 for publication that could have appeared to influence the work reported in this paper.

\section{CRediT authorship contribution statement}

519 Conceptualization: Jagabandhu Dixit; Methodology: Navdeep Agrawal, Laxmi Gupta, 520 Jagabandhu Dixit; Formal analysis and investigation: Navdeep Agrawal, Laxmi Gupta; 521 Validation: Navdeep Agrawal, Laxmi Gupta, Jagabandhu Dixit; Visualization: Navdeep 522 Agrawal, Laxmi Gupta; Writing - original draft preparation: Navdeep Agrawal, Laxmi Gupta; 523 Writing - review and editing: Jagabandhu Dixit, Sujit Kumar Dash; Resources: Jagabandhu 524 Dixit; Supervision: Jagabandhu Dixit

\section{References}

Abramowitz M, Stegun IA (1972) Handbook of mathematical functions: with formulas, graphs, and mathematical tables. National Bureau of Standards Washington, DC:(Vol 55, 
529 Agrawal N, Gupta L, Dixit J (2021) Assessment of the socioeconomic vulnerability to seismic 530 hazards in the National Capital Region of India using factor analysis. Sustainability 13(17):9652

532 Al-Dogom D, Schuckma K, Al-Ruzouq R (2018) Geostatistical seismic analysis and hazard 533 assessment, United Arab Emirates. International Archives of the Photogrammetry, Remote Sensing and Spatial Information Sciences 42 (3/W4)

535

Anbazhagan P, Bajaj K, Matharu K, Moustafa SS, Al-Arifi NS (2019) Probabilistic seismic hazard analysis using the logic tree approach-Patna district (India). Natural Hazards and

Anbazhagan P, Kumar A, Sitharam TG (2013) Ground motion prediction equation considering combined dataset of recorded and simulated ground motions. Soil Dynamics and Earthquake Engineering 53:92-108

Armaș I, Gavriș A (2013) Social vulnerability assessment using spatial multi-criteria analysis

Atkinson GM, Boore DM (2003) Empirical ground-motion relations for subduction-zone (SEVI model) and the Social Vulnerability Index (SoVI model)-a case study for Bucharest,

Bahuguna A, Sil A (2020) Comprehensive seismicity, seismic sources and seismic hazard assessment of Assam, North East India. Journal of Earthquake Engineering 24(2):254-297

Baro O, Kumar A, Ismail-Zadeh A (2018) Seismic hazard assessment of the Shillong Plateau, 550 India. Geomatics, Natural Hazards and Risk 9(1):841-861 (last assessed: 20 September 2021) 
553 Brandt K, Graham L, Hawthorne T, Jeanty J, Burkholder B, Munisteri C, Visaggi C (2020) 554 Integrating sketch mapping and hot spot analysis to enhance capacity for community-level 555 flood and disaster risk management. The Geographical Journal 186(2):198-212

556 Birkmann J (2013) Measuring vulnerability to natural hazards: towards disaster resilient 557 societies. (i9789280811353). United Nations University Press, Tokyo, Japan

558 Census of India (2011) Provisional Population Totals. New Delhi: Office of the Registrar 559 General and Census Commissioner. https://censusindia.gov.in/

560 Cutter SL (1996) Vulnerability to environmental hazards. Progress in Human Geography 20(4): 529-539

562 Cutter SL, Barnes L, Berry M, Burton C, Evans E, Tate E, Webb J (2008) A place-based model 563 for understanding community resilience to natural disasters. Global Environmental Change

Cutter SL, Boruff BJ, Shirley WL (2003) Social vulnerability to environmental hazards. Social Science Quarterly 84(2):242-261

Das R, Sharma, ML, Wason HR (2016) Probabilistic seismic hazard assessment for northeast India region. Pure and Applied Geophysics 173(8):2653-2670

Das S, Hazra S, Haque A, Rahman M, Nicholls RJ, Ghosh A, Ghosh T, Salehin M, de Campos RS (2021) Social vulnerability to environmental hazards in the Ganges-BrahmaputraMeghna delta, India and Bangladesh. International Journal of Disaster Risk Reduction 53:101983.

Depietri Y, Welle T, Renaud FG (2013) Social vulnerability assessment of the Cologne urban area (Germany) to heat waves: links to ecosystem services. International Journal of Disaster Risk Reduction 6:98-117

Depietri Y (2020) The social-ecological dimension of vulnerability and risk to natural hazards. 
Derakhshan S, Hodgson ME, Cutter SL (2020) Vulnerability of populations exposed to seismic risk in the state of Oklahoma. Applied Geography 124:102295

Dixit J, Raghukanth STG, Dash SK (2016) Spatial distribution of seismic site coefficients for Guwahati city. In Geostatistical and Geospatial Approaches for the Characterization of Natural Resources in the Environment 533-537

Dutta SC, Halder L, Sharma RP (2021) Seismic vulnerability assessment of low to mid-rise RC buildings addressing prevailing design and construction practices in the Northeastern region of the Indian subcontinent: A case study based approach. Structures 33:1561-1577

Fatemi F, Ardalan A, Aguirre B, Mansouri N, Mohammadfam I (2017) Social vulnerability indicators in disasters: findings from a systematic review. International Journal of Disaster Risk Reduction 22:219-227

Frigerio I, Ventura S, Strigaro D, Mattavelli M, De Amicis M, Mugnano S, Boffi M (2016) A GIS-based approach to identify the spatial variability of social vulnerability to seismic hazard in Italy. Applied Geography 74:12-22

Gardner JK, Knopoff L (1974) Is the sequence of earthquakes in Southern California, with aftershocks removed, Poissonian?. Bulletin of the Seismological Society of America 64(5):1363-1367

Ge Y, Dou W, Gu Z, Qian X, Wang J, Xu W, Shi P, Ming X, Zhou X Chen Y (2013) Assessment of social vulnerability to natural hazards in the Yangtze River Delta, China. Stochastic Environmental Research and Risk Assessment 27(8):1899-1908

Ghione F, Poggi V, Lindholm C (2021) A hybrid probabilistic seismic hazard model for Northeast India and Bhutan combining distributed seismicity and finite faults. Physics and Chemistry of the Earth, Parts A/B/C, 103029

Gupta ID (2002) The state of the art in seismic hazard analysis. ISET Journal of Earthquake Technology 39(4):311-346 
Indian Standard (2016) Criteria for earthquake resistance design of structures, Fifth revision, Part-I, New Delhi

ISC, International Seismological Centre, ISC-GEM Earthquake Catalogue 2021, URL: https://doi.org/10.31905/d808b825 (last accessed: 20 September 2021)

Jain SK, Roshan AD, Arlekar JN, Basu PC (2000) Empirical attenuation relationships for the Himalayan earthquakes based on Indian strong motion data. In Proceedings of The Sixth International Conference on Seismic Zonation 12-15

Karuppusamy B, Leo George S, Anusuya K, Venkatesh R, Thilagaraj P, Gnanappazham L, Kumaraswamy K, Balasundareshwaran AH, Balabaskaran NP (2021) Revealing the socioeconomic vulnerability and multi-hazard risks at micro-administrative units in the coastal plains of Tamil Nadu, India. Geomatics, Natural Hazards and Risk 12(1):605-630

Kijko A, Sellevoll MA (1989) Estimation of earthquake hazard parameters from incomplete data files. Part I. Utilization of extreme and complete catalogues with different threshold magnitudes. Bulletin of the Seismological Society of America 79(3):645-654

Kijko A (2004) Estimation of the maximum earthquake magnitude, m max. Pure and Applied Geophysics 161(8):1655-1681

Kolathayar S (2021) Recent seismicity in Delhi and population exposure to seismic hazard. Natural Hazards. https://doi.org/10.1007/s11069-021-04936-x

Kramer SL (1996) Geotechnical Earthquake Engineering. Pearson Education India

Maiti S, Jha SK, Garai S, Nag A, Bera AK, Paul V, Upadhaya RC, Deb SM (2017) An assessment of social vulnerability to climate change among the districts of Arunachal Pradesh, India. Ecological Indicators 77:105-113.

Martins VN, e Silva DS, Cabral P (2012) Social vulnerability assessment to seismic risk using multicriteria analysis: the case study of Vila Franca do Campo (São Miguel Island, Azores, Portugal). Natural Hazards 62(2):385-404 
628

629

630

631

632

633

634

635

636

637

638

639

640

641

642

643

644

645

646

647

648

649

650

651

652

Morrow BH (1999) Identifying and mapping community vulnerability. Disasters 23:1-18

Nath SK, Thingbaijam KKS (2012) Probabilistic seismic hazard assessment of India. Seismological Research Letters 83(1):135-149

Nath SK, Thingbaijam KKS, Maiti SK, Nayak A (2012) Ground-motion predictions in Shillong region, Northeast India. Journal of Seismology 16(3):475-488

NCS-MoES, National Center for Seismology, Ministry of Earth Sciences, Government of India. URL: https://seismo.gov.in/MIS/riseq/earthquake (last accessed: 20 September 2021)

NDMA (2010) Development of probabilistic seismic hazard map of India; Technical Report by National Disaster Management Authority, Government of India

Pallav K, Raghukanth STG, Singh KD (2012) Probabilistic seismic hazard estimation of Manipur, India. Journal of Geophysics and Engineering 9(5):516-533

Raghukanth STG, Dash SK (2010) Deterministic seismic scenarios for Northeast India. Journal of Seismology 14(2):143-167

Raghukanth STG, Dixit J, Dash SK (2011) Ground motion for scenario earthquakes at Guwahati city. Acta Geodaetica et Geophysica Hungarica 46:326-346

Raghukanth STG, Iyengar RN (2006) Seismic hazard estimation for Mumbai city. Current Science, 1486-1494

Ramkrishnan R, Kolathayar S, Sitharam TG (2020) Development of new ground motion prediction equation for the North and Central Himalayas using recorded strong motion data. Journal of Earthquake Engineering, 1-24 DOI: 10.1080/13632469.2020.1778586

Rydelek PA, Sacks IS (1989) Testing the completeness of earthquake catalogues and the hypothesis of self-similarity. Nature 337(6204):251-253

Sarmah T, Das S (2018) Earthquake vulnerability assessment for RCC buildings of Guwahati City using rapid visual screening. Procedia Engineering 212:214-221 
653 Sharma ML, Malik S (2006) Probabilistic seismic hazard analysis and estimation of spectral 654 strong ground motion on bedrock in northeast India. In 4th International Conference on Earthquake Engineering, Taipei, Taiwan, October 12-13, 2006, (Paper no. 15)

Sharma, S. 1996. Applied Multivariate Techniques. Wiley, Canada.

657

658

659

660

661

662

663

664

665

666

667

668

669

670

671

672

673

674

675

676

Siagian TH, Purhadi P, Suhartono S, Ritonga H (2014) Social vulnerability to natural hazards in Indonesia: driving factors and policy implications. Natural Hazards 70(2):1603-1617

Sil A, Sitharam TG, Kolathayar S (2013) Probabilistic seismic hazard analysis of Tripura and Mizoram states. Natural Hazards 68(2):1089-1108

Sitharam TG, Sil A (2014) Comprehensive seismic hazard assessment of Tripura and Mizoram states. Journal of Earth System Science 123(4):837-857

Stepp JC (1972) Analysis of completeness of the earthquake sample in the Puget Sound area and its effect on statistical estimates of earthquake hazard. In Proc. of the 1st International Conference on Microzonazion, Seattle 2:897-910

USGS NEIC. US Geological Survey National Earthquake Information Center 2021, URL: http://earthquake.usgs.gov/earthquakes (last accessed: 20 September 2021)

Stiphout TV, Zhuang J, Marsan D (2012) Seismicity declustering, Community Online Resource for Statistical Seismicity Analysis, DOI: 10.5078/corssa-52382934

Verma RK, Kumar GK (1987) Seismicity and the nature of plate movement along the Himalayan arc, Northeast India and Arakan-Yoma: a review. Tectonophysics 134(13):153-175

Verma R (2018) The major drainage systems in the Northeastern region of India. In The Indian Rivers (429-464). Springer, Singapore

Wason HR, Das R, Sharma ML (2012) Magnitude conversion problem using general orthogonal regression. Geophysical Journal International 190(2):1091-1096 
677 Wiemer S, Wyss M (2000) Minimum magnitude of completeness in earthquake catalogs: 678 examples from Alaska, the western United States, and Japan. Bulletin of the Seismological $679 \quad$ Society of America 90(4):859-869

680 Wiemer S (2001) A software package to analyze seismicity: ZMAP. Seismological Research $681 \quad$ Letters $72(3): 373-382$

682 Woessner J, Wiemer S (2005) Assessing the quality of earthquake catalogues: Estimating the 683 magnitude of completeness and its uncertainty. Bulletin of the Seismological Society of $684 \quad$ America 95(2):684-698

685 Wood NJ, Burton CG, Cutter SL (2010) Community variations in social vulnerability to 686 Cascadia-related tsunamis in the US Pacific Northwest. Natural Hazards 52(2):369-389

687 Zhuang J, Ogata Y, Vere-Jones D (2002) Stochastic declustering of space-time earthquake 688 occurrences. Journal of the American Statistical Association, 97(458):369-380 